\title{
Computational Investigation of Acene-Modified Zinc-Porphyrin Based Sensitizers for Dye-Sensitized Solar Cells
}

\author{
Yan Fang Liu, ${ }^{\dagger}$ Jing Guan, ${ }^{\dagger}$ Deping Hu, ${ }^{\dagger \dagger}$ Likai Du, ${ }^{\dagger}$ Hao Sun, ${ }^{\S, \|}$ Jun Gao, $^{\perp}$ Jin Zhao, ${ }^{*}, \S, \|$
} and Zhenggang Lan*, ${ }^{*}$,

${ }^{\dagger}$ The Key Laboratory of Biobased Materials, Qingdao Institute of Bioenergy and Bioprocess Technology, Chinese Academy of Sciences, Qingdao, Shandong 266101, People's Republic of China

‡University of Chinese Academy of Sciences, Beijing 100049, People’s Republic of China

${ }^{\S}$ Department of Physics and Hefei National Laboratory for Physical Sciences at the Microscale, and "Synergetic Innovation Center of Quantum Information and Quantum Physics, University of Science and Technology of China, Hefei, Anhui 230026, People's Republic of China

${ }^{\perp}$ Key Laboratory of Theoretical and Computational Chemistry in Universities of Shandong, Shandong University, Jinan, 250100, People's Republic of China

\section{Supporting Information}

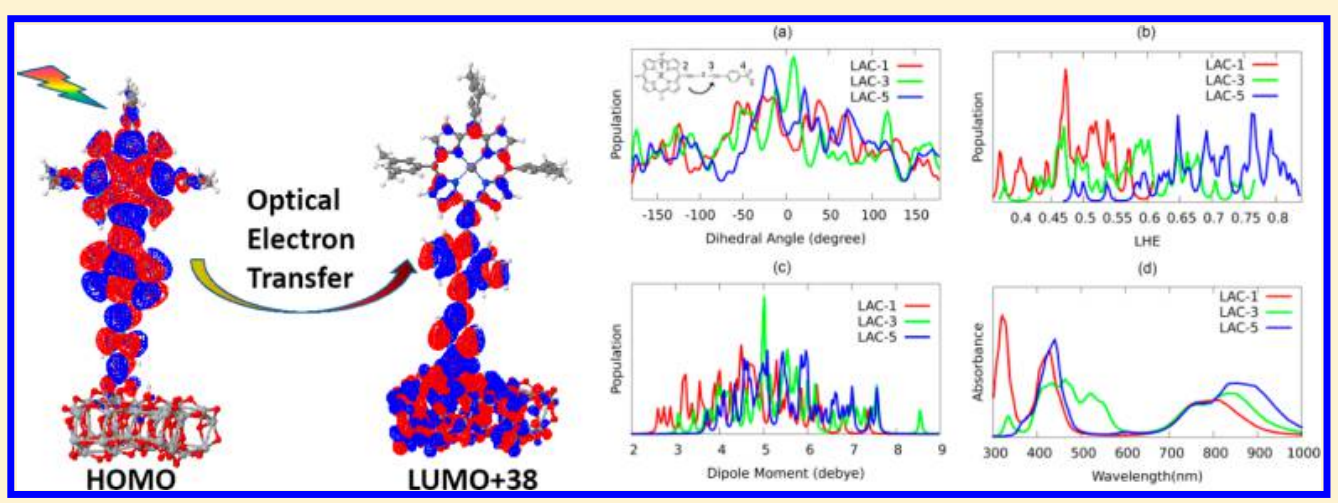

ABSTRACT: A series of acene-modified zinc-porphyrin dyes (benzene to pentacene, denoted as LAC-1 to LAC-5) were chosen to examine their performance as photosensitizers in dye-sensitized solar cells (DSSCs). Their structural, electronic, and optical properties were investigated at the DFT/TDDFT levels using various theoretical models (i.e., the gas phase model and the implicit/explicit solvent model). The dye@ $\mathrm{TiO}_{2}$ complex was used to investigate the dye/semiconductor interfaces using both the cluster and periodic models. After a careful examination of the dependence of the results on different theoretical approaches, some basic principles could be derived based on the theoretical investigation of structure-function relationships in isolated dyes and dye- $-\mathrm{TiO}_{2}$ assemblies. Based on these ideas, some general suggestions can be proposed for the future design of dyes for use in DSSCs. For instance, the DFT functionals used in estimating the critical parameters for DSSCs should be carefully validated. Sometimes the performances of the DFT functionals can be improved by a specific energy-shift correction to compensate for systematic errors. Benchmark calculations indicated that the best approach for depicting the reduction potentials is either the M06-2X functional combined with the formula $\Delta E_{\mathrm{red}}=\left(E^{0}-E^{-}\right)_{\mathrm{GS}}$ or the B3LYP functional combined with Koopman's Theorem. The best functional for estimating the excitation energies was found to be LC- $\omega$ PBE. The impact of significant thermal fluctuations on the optoelectronic properties of dyes may also be an important consideration in the prediction of more efficient dyes for use DSSCs. In contrast to the selection of DFT functionals, both the cluster and periodic models resulted in consistent views of the dye- $\mathrm{TiO}_{2}$ interactions, indicating that the use of either model should achieve reasonable results at least in the qualitative manner.

\section{INTRODUCTION}

Dye-sensitized solar cells (DSSCs) were introduced by Grätzel in 1991 and were believed to be a novel type of excellent photovoltaic devices due to their low costs and relatively high energy-conversion efficiency. ${ }^{1,2}$ The performance of DSSCs is highly relevant to photosensitizers composed of dye molecules, which should in principle have wide absorption bands with high intensities. After photoexcitation, an electron from the excited state of a dye molecule is injected into the conduction band of the semiconductor. Later on, the regeneration of the dye is required. ${ }^{3}$

Received: July 31, 2014

Revised: March 24, 2015

Published: March 30, 2015 
In past decades, a large number of photosensitizers have been synthesized for use in DSSCs, including metal complexes, porphyrin and phthalocyanine-based dyes, and organic dyes. ${ }^{4}$ Among these, some ruthenium dyes (such as N3 ${ }^{5}$ and N719 dyes) have achieved a high sunlight-to-electricity conversion efficiency (PCE > 11\%), while their further applications are greatly hindered by the inclusion of expensive and rare transition metals (such as Ru). ${ }^{7}$ After significant efforts in last decades, the cheaper organic dyes have reached the similar PCE $(>12 \%){ }^{8}$ Alternatively, porphyrin-based dyes, a novel type of dyes introduced by Grätzel and co-workers, have shown great potential due to their high PCE (>13.0\%). ${ }^{9}$

Diau and co-workers reported the development of a series of dyes (LAC-1 to LAC-5) connecting a Zn-porphyrin core to different acenyl linkages. These dyes are good candidates for use in DSSCs due to their potentially excellent PCEs (Scheme 1). ${ }^{10}$

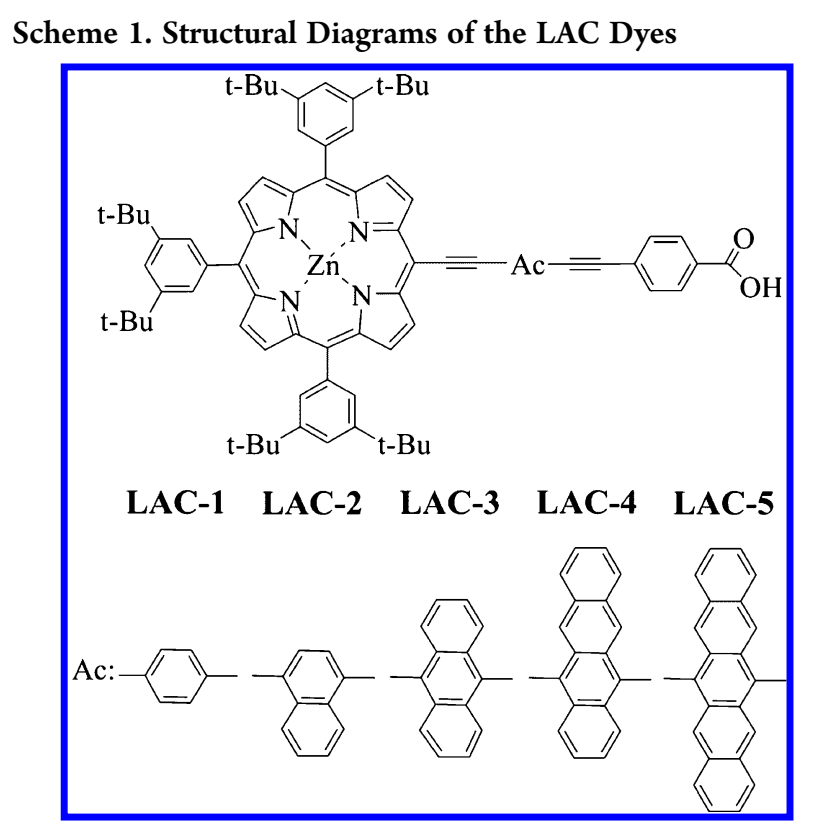

When the $\pi$-conjugation is enhanced from LAC- 1 to LAC- 3 , the PCE also increases monotonically. Of these dyes, the LAC-3 dye containing the anthracene group shows excellent performance that is comparable to the traditional N719 dye under the same experimental conditions. The LAC-4 dye contains a tetracene group and the LAC-5 dye contains a pentacene group; both dyes seem to display even broader and stronger low-band absorptions, though their PCEs are too small to achieve satisfactory performances. As suggested by a previous study, ${ }^{10}$ this low efficiency may be due to the nonradiative relaxation of the molecules. A similar interpretation was suggested in a study of a series of metal-free acene-modified triphenylamine dyes. ${ }^{11}$ Because the series of LAC dyes described above clearly demonstrate the interplay between structure and functionality, these compounds are excellent prototypes for exploring the mechanisms that control the performances of porphyrin-based dyes.

It is well-known that conducting a laboratory screen for effective dyes with good sunlight-to-electricity conversion efficiencies is a very time-consuming and expensive task. As an alternative tool, theoretical modeling can be used to reduce the costs and tedium of laboratory screens. The efficient injection of electrons requires that the excited-state oxidation potential (ESOP) is at least $\sim 0.2 \mathrm{eV}$ higher than the $\mathrm{TiO}_{2}$ conduction band minimum (CBM), while the ground-state oxidation potential (GSOP) must be at least $\sim 0.2 \mathrm{eV}$ lower than the redox mediator potential. ${ }^{12}$ Some DFT calculations have been used to develop a comprehensive understanding of the ground-state properties of isolated dyes and complex dye@ $\mathrm{TiO}_{2}$ systems. ${ }^{10,11,13-38}$ Many of these calculations have focused on Ru-complex dyes such as N3-type dyes. ${ }^{25,39-42}$ Both cluster and periodic models have been used to investigate the dye $@ \mathrm{TiO}_{2}$ systems in order to mimic the absorption of the dye molecule onto the $\mathrm{TiO}_{2}$ surface. ${ }^{11,13,15-17,23,25,43}$ These works clarified the dye- $\mathrm{TiO}_{2}$ connection pattern and described their electronic couplings. With the development of computational approaches, the excited states of isolated dyes ${ }^{44,45}$ and dye@ $@ \mathrm{TiO}_{2}$ cluster systems can be directly examined at the TDDFT level in a qualitative manner. ${ }^{30,33,46-49}$ This strategy can provide a more accurate estimation of the absorption spectra and excited state oxidation potentials (ESOP) of isolated dyes as well as the alignments of local excited states and charge transfer states of a dye@ $\mathrm{TiO}_{2}$ system. ${ }^{13-15,17,25}$ The molecular dynamics (MD) and TDDFT approaches have been used to investigate the influence of thermal fluctuation on the structure-property relationships ${ }^{51,53,54}$ of isolated dyes, ${ }^{40}$ dye@ $\mathrm{TiO}_{2}$ complexes. ${ }^{50-52}$ Furthermore, ultrafast photoinduced electron transfer dynamics from dyes to $\mathrm{TiO}_{2}$ is also an interesting topic that has been investigated using various recently developed methods, including pure electronic dynamics, semiclassical dynamics, and full quantum dynamics. $35,40,55-65$

In order to overcome the deficiencies of $\mathrm{DFT}^{66}$ the GW method based on the Green function ${ }^{66-68}$ is a promising approach that seems to provide better descriptions of crystalline $\mathrm{TiO}_{2}{ }^{69}$ isolated dyes, ${ }^{70}$ and dye@ $@ \mathrm{TiO}_{2}$ systems. ${ }^{66,71}$ However, the application of the GW method is limited by its large computational cost. The flaws of the TDDFT method are wellknown $^{72,73}$ such as the underestimation of the transition energies of the excited states with charge transfer characters, the poor descriptions of doubly or highly excited states, and the systematic errors related to large $\pi$-extended systems. ${ }^{74,75}$ Thus, some theoretical calculations have tried to improve the computational accuracy by employing high-level approaches such as the CC2 method, ${ }^{76,77}$ the DFT-MRCI method, ${ }^{77-79}$ the Equation-ofMotion Coupled Cluster (EOM-CC) method, ${ }^{80}$ EOM-CCSD, ${ }^{80}$ and the Bethe-Salpeter equation (BSE). ${ }^{67,81,82}$ However, all of these methods suffer from huge computational costs. Thus, achieving reasonable accuracies for large systems at reduced computational costs remains a great challenge.

Calculation methods such as the use of DFT functionals and pre-established models of realistic systems play important roles in the theoretical modeling and design of effective dyes. Thus, it is important to compare the results obtained from the different theoretical approaches. Additionally, the structural flexibility of dyes may play a potential role in the interactions with $\mathrm{TiO}_{2}$ substrates. For example, intermolecular interactions at the heterointerfaces composed of multiple dye molecules, the semiconductor surface and the electrolyte are believed to be essential in determining the overall PCE of the DSSCs. ${ }^{25}$ Thus, all of these important issues should be carefully considered in order to reasonably design novel dyes from a computational perspective.

Based on a few initial studies of porphyrin-dye@ $\mathrm{TiO}_{2}$ systems, ${ }^{15,18-21}$ we sought to comprehensively investigate a series of acene-modified zinc-porphyrin sensitizers (LAC), as well as LAC@ $\mathrm{TiO}_{2}$ complexes, using various methods and models. The isolated dyes were first investigated using the DFT/TDDFT approaches. Then, the MD simulation of the LAC dyes in the 
Table 1. Overview of the Theoretical Models and Methods in This Work

\begin{tabular}{|c|c|c|c|c|}
\hline system & model & level & functional & properties \\
\hline \multirow[t]{11}{*}{ isolated dye } & gas phase & DFT/TDDFT & PBE & GSOP/GSRP \\
\hline & & & B3LYP & $E_{\mathrm{vet}} / \mathrm{ESOP}$ \\
\hline & & & BH\&HLYP & $\varepsilon_{\mathrm{HOMO}} / \varepsilon_{\mathrm{LUMO}}$ \\
\hline & & & CAM-B3LYP & $\Delta G_{\text {inject }}$ \\
\hline & implicit solvent (THF) & & $\omega \mathrm{B} 97 \mathrm{XD}$ & frontier MO \\
\hline & & & LC- $\omega$ PBE & $f /$ LHE \\
\hline & & & M062X & \\
\hline & implicit/explicit solvent (THF) & $\mathrm{MD}$ & CAM-B3LYP & geometric parameters \\
\hline & & & & LHE \\
\hline & & DFT/TDDFT & & dipole moment $(\mu)$ \\
\hline & & & & absorption spectrum \\
\hline \multirow[t]{4}{*}{ dye@ $\mathrm{TiO}_{2}$} & cluster model & DFT & PBE & geometric properties \\
\hline & & & B3LYP & orbital alignments \\
\hline & & & BH\&HLYP & critical MO \\
\hline & periodic model & & PBE & DOS/PDOS \\
\hline
\end{tabular}

THF solution and the TDDFT calculation were combined in order to gain some qualitative information about the conformational flexibility of the dye molecules. Later, the dye@ $\mathrm{TiO}_{2}$ systems were studied using both the cluster and periodic models. These results may provide a preliminary understanding of the performance of the various theoretical models in the studies of DSSCs. After carefully evaluating the currently available models and methods, we offer some suggestions on how to theoretically predict the performance of dyes with reasonable accuracy. Most importantly, based on the careful evaluations of these different theoretical approaches, we offer some general commentaries and propose some rules that are critical for the theoretical design of dyes in the future.

\section{MODELS AND METHODS}

Throughout this work, isolated dyes and dye@ $\mathrm{TiO}_{2}$ systems were investigated, as summarized in Table 1. The isolated dyes were carefully studied at the DFT/TDDFT level using the gas phase and implicit solvent models, while the dye@ $\mathrm{TiO}_{2}$ complex was studied at the DFT level using both the cluster and periodic models. Additionally, the flexibility of the isolated dye in the explicit THF solvent model was studied using classical molecular dynamics (MD) simulations, followed by TDDFT calculations.

2.1. Isolated Dyes. The stable ground-state geometries of the isolated LAC dyes in the gas phase were optimized at the B3LYP ${ }^{83,84} /$ SVP level. We also optimized the structure of LAC-1 with the BH\&HLYP $83,85,86$ and $\omega \mathrm{B}^{87 X^{87}}$ functionals to evaluate the accuracy of the B3LYP functional. The differences between the optimized geometries obtained using different functionals were limited, as the root-mean-square deviations (RMSD) of the optimized geometries were $0.1 \AA$ at the BH\&HLYP level and 0.4 $\AA$ at the $\omega$ B97XD level, with respect to their counterparts at the B3LYP functional level (Figure S1 and Table S1a in SI). Additionally, the results indicated that BH\&HLYP, $\omega$ B97XD, and B3LYP provided similar electronic properties, including the oxidized, reduced, and neutral ground state species (Figure S1 and Table S1b in SI). Therefore, it is reasonable to optimize the geometries at the B3LYP/SVP level for a qualitative analysis.

Recently, the accuracy of the exchange-correlation functionals (i.e., the effects of the Hartree-Fock exchange) has been carefully discussed by De Angelis and others. ${ }^{88-90}$ The B3LYP, BH\&HLYP, CAM-B3LYP, ${ }^{91} \omega$ B97XD, LC- $\omega$ PBE, ${ }^{92-94}$ $\mathrm{MPW} 1 \mathrm{~K},{ }^{95}$ and $\mathrm{M} 062 \mathrm{X}^{96}$ functionals have been proposed to give the reasonable descriptions of several dyes. However, these calculations have also indicated that the performances of the DFT functionals are highly dependent on the particular dye systems under investigation. Thus, for the current series of acenemodified zinc-porphyrin sensitizer (LAC) dye systems, it is still important to perform the systematic benchmark calculations in order to determine the reliability of different functionals. Thus, several density functionals with the TZVP basis set, including $\mathrm{PBE},{ }^{97} \mathrm{~B} 3 \mathrm{LYP}$, and $\mathrm{BH} \& \mathrm{HLYP}$, were chosen for calculating the single-point energy at the B3LYP/SVP optimized geometries. These calculations were sped up by employing the RI and RIJCOSX approximations for pure and hybrid functionals, respectively, ${ }^{98,99}$ which are available in ORCA. ${ }^{100,101}$ Further single-point calculations were performed using several rangeseparated functionals (CAM-B3LYP, $\omega$ B97XD, and LC- $\omega$ PBE) as well as the meta-GGA functional (M062X) and the 6-311G** basis sets, which were implemented in Gaussian 09. ${ }^{102}$

The TDDFT calculations were performed for the stable ground state geometries of the isolated dyes using the seven functionals listed above (the PBE/SVP, B3LYP/SVP, and BH\&HLYP/SVP calculations were used, whereas the CAMB3LYP/6-31G*, $\omega$ B97XD/6-31G*, LC- $\omega \mathrm{PBE} / 6-31 \mathrm{G}^{*}$, and M062X/6-31G* functionals were used). In order to account for the solvent effects (in THF solvent), the single point energies of the isolated LAC dyes were calculated using the conductor-like screening model (COSMO) in ORCA and the polarizable continuum solvation models (PCM) in Gaussian 09. For the solvent THF, the dielectric constant and probe radius were set to 7.0 and $2.71 \AA$, respectively. Additionally, the differences between these two implicit solvent models were evaluated (Table S2a in SI).

The dynamics behaviors of isolated dyes in the explicit THF solvent were investigated using classical MD simulations. The initial configuration was obtained by randomly depositing the LAC and THF molecules in a cubic box (Figure S2 in SI). The UFF force field was used in the MD simulation and the periodic boundary conditions were applied in all simulations. The leapfrog algorithm was adopted to integrate the motion equations with a time step of $1 \mathrm{fs}$. The temperature was maintained at $298.15 \mathrm{~K}$ using a Nose thermostat. ${ }^{103}$ First, the initial configurations were minimized to remove the possibility of overlap. After this, the system was equilibrated for $1 \mathrm{~ns}$ at $343.15 \mathrm{~K}$, and then the data were collected every 5000 time steps for 500 ps. The potential and the density were monitored in the production 
stage. Finally, from the MD trajectory, snapshots of the system at different times were taken and the optical properties of each snapshot configuration were analyzed at the TDDFT level. The excitation parameters were estimated using the TDDFT calculations at the CAM-B3LYP/6-31G* level. Similar approaches have been used in other works. ${ }^{25,50}$

The sunlight-to-electricity conversion efficiency $(\eta)$ of a solar cell device is determined by the following equation:

$$
\eta=\frac{V_{\mathrm{OC}} J_{\mathrm{SC}}}{P_{\text {inc }}} \mathrm{FF}
$$

where $V_{\mathrm{OC}}$ is the open-circuit photo voltage; $J_{\mathrm{SC}}$ is the shortcircuit current density; FF is the fill factor, which is constant for a specific system; and $P_{\text {inc }}$ is the incident solar power.

In DSSCs, the semiconductor conduction band shift $(\Delta C B)$ is a key parameter in determining the $V_{\mathrm{OC}}$, while $J_{\mathrm{SC}}$ can be wellestimated from the light-harvesting efficiency $(\operatorname{LHE}(\lambda))$ and the driving force $\left(\Delta G_{\text {inject }}\right)$ of electrons injected from the excited states of dye to the $\mathrm{TiO}_{2}$.

The $\Delta \mathrm{CB}$ can be expressed as a function of the dipole moment $\left(\mu_{\text {normal }}\right)$ of a dye. ${ }^{104}$ The $\operatorname{LHE}(\lambda)$ of the dye is approximated as $\operatorname{LHE}(\lambda)=1-10^{-f}$, where $f$ is the oscillator strength. ${ }^{105}$ The driving force of electron injection $\left(\Delta G_{\text {inject }}\right)$ can be estimated using the relationship $\Delta G_{\text {inject }}=E^{\text {dye } *}-E_{\mathrm{CB}}$, where $E^{\text {dye } *}$ is the excited oxidation potential of the dye and $E_{\mathrm{CB}}$ is the conduction band edge of the $\mathrm{TiO}_{2}$.

Two additional key parameters to determine the performance of dyes are the GSOP and ESOP, which are amenable to the theoretical modeling of an isolated dye. The GSOP is the free energy difference between the oxidized and neutral ground state species at their optimized geometries, termed $\left(G^{+}-G^{0}\right)_{\mathrm{Gs}}{ }^{47}$ However, it is not a trivial task to employ this procedure in large systems due to the large computational cost of accounting for molecular vibrations, the difficulty to account for solvent reorganization, and other factors. In the present work, two approximated approaches ${ }^{47,106}$ were used to qualitatively estimate the GSOP: (1) the electronic energy difference between the neutral and the oxidized species at their corresponding optimized geometries $\left(\Delta E_{\mathrm{ox}}=\left(E^{+}-E^{0}\right)_{\mathrm{GS}}\right)$; and (2) Koopman's Theorem. Similar procedures were also taken to estimate the ground-state reduced potential (GSRP) using $\Delta E_{\text {red }}=\left(E^{0}-E^{-}\right)_{\mathrm{GS}}$. De Angelis and co-workers ${ }^{47}$ also showed that $\Delta E_{\text {red }}$ and $-\varepsilon_{\text {LUMO }}$ could provide comparable results for the same set of dyes, suggesting the reasonable accuracy of Koopman's Theorem in the description of the GSRP.

The ESOP can be obtained by subtract the adiabatic lowest excited energy $\left(E_{0-0}\right)$ from the GSOP: ${ }^{12}$

$$
\mathrm{ESOP} \approx\left(G^{+}-G^{0}\right)_{\mathrm{GS}}-E_{0-0}
$$

where $E_{0-0}$ denotes the energy difference between the optimized ground-state and excited-state minima. In this work, $E_{0-0}$ was approximated as the lowest vertical excitation energy at the ground-state geometry due to the exaggerated computational cost of the excited-state optimization. A similar approximation was successfully used in the work of De Angelis and others. ${ }^{14,47}$ For completeness, Koopman's Theorem was also used to estimate the ESOP, as suggested by several previous works. ${ }^{11,14,22,107-111}$

2.2. Dye@ $\mathrm{TiO}_{2}$ Systems. 2.2.1. Cluster Model. The $\mathrm{TiO}_{2}$ clusters were modeled using $\left(\mathrm{TiO}_{2}\right)_{38}$ and $\left(\mathrm{TiO}_{2}\right)_{68}$, two anatase clusters consisting of 38 and 68 units, respectively, that have been widely used in many previous works. ${ }^{15,46,112-115}$ The LAC dye was absorbed in a monodentate or bidentate binding mode onto the (101) surface of the optimized $\mathrm{TiO}_{2}$ clusters. The LAC@ $\mathrm{TiO}_{2}$ complexes were optimized at the PBE/DNP level using the DMol3 program package ${ }^{116,117}$ from Materials Studio. Then, single-point calculations were performed in TURBOMOLE at the PBE/SVP, B3LYP/SVP and BH\&HLYP/SVP levels. ${ }^{118}$ To check the accuracy of the optimized structures obtained using DMol3, we also optimized the LAC-3@ $\left(\mathrm{TiO}_{2}\right)_{38}$ and LAC$3 @\left(\mathrm{TiO}_{2}\right)_{68}$ clusters at the PBE/SVP level using the MARI ${ }^{119}$ approximation in the TURBOMOLE program.

It is very time-demanding or even impossible to directly describe the excited states when the size of the dye@ $\mathrm{TiO}_{2}$ system is increased. In order to provide theoretical insights into the electron injection, a more practical method can be employed $^{112,120}$ in which the orbital alignments and electronic DOS (density of states) are examined only with the groundstate DFT calculations. In this way, the electronic couplings can be analyzed, and the electron injection time ( $\tau$, in fs) between the LAC dye and the $\mathrm{TiO}_{2}$ substrate can be estimated using the Newns-Anderson approach. ${ }^{121}$

2.2.2. Periodic Model. The anatase $\mathrm{TiO}_{2}$ (101) surface was modeled as a periodic slab from a $(4 \times 7)$ supercell containing eight $\mathrm{O}-\mathrm{Ti}-\mathrm{O}$ atomic layers (112 units of $\mathrm{TiO}_{2}, 336$ atoms in total). The slab was separated by a vacuum region of $40 \AA$ thickness, which was enough to avoid spurious interactions between the periodic images. The dye was adsorbed onto the upper side ( $\mathrm{z}$ direction) of the slab. Binding sites on the $\mathrm{TiO}_{2}$ (101) surface consisted of the 2-fold coordinated oxygen atoms and the 5-fold coordinated titanium atoms. The atoms of the bottom four $\mathrm{O}-\mathrm{Ti}-\mathrm{O}$ layers were fixed in their lattice positions, whereas the top-four atomic layers of $\mathrm{TiO}_{2}$ along with the dye were allowed to relax.

Periodic calculations were carried out using the plane-wave technique implemented in the Vienna ab initio simulation package (VSAP). ${ }^{122,123}$ The nonlocal exchange and correlation energies were also treated with the PBE functional. ${ }^{97}$ The projector-augmented wave (PAW) approach ${ }^{124}$ was adopted to describe the interaction of the ionic cores with the valence electrons, and the cutoff energy was set to $380 \mathrm{eV}$. The optimization was performed using the conjugated gradient method, with the forces on each atom converging to a tolerance of $0.02 \mathrm{eV} / \AA ̊$. Due to the large supercell, only the Gamma point was utilized for the geometry optimization. In the calculation of the DOS, a much finer $(4 \times 4 \times 1)$ Gamma point mesh was used. We did not consider the spin polarization in the current calculation.

\section{RESULTS}

3.1. Properties of LAC Dyes. Recent theoretical studies have discussed the dependence of the electronic and photophysical properties of specific dyes on xc functionals. . $^{4,88-90}$ Thus, the GSOP values for LAC dyes were estimated using a few functionals (Figure 1a,b). For completeness, the GSRP values are also given (Figure $1 \mathrm{c}, \mathrm{d}$ ). The calculated negative values of the GSOP for all dyes in the THF solution were $0.1-0.59 \mathrm{eV}$ lower than the $I^{-} / I_{3}^{-}$redox potential $(-4.8 \mathrm{eV})$, as shown in Table S2b in SI. All the computed results suggest a consistent tendency for the GSOP to decrease as the molecular conjugation increases from LAC-1 to LAC-5. However, the larger ratio of the HartreeFock exchange seems to increase the GSOP and decrease the GSRP. Among all selected functionals, the GSRP values estimated using the GGA functional PBE and the meta-hybrid functional M062X were close to the experimental values, 


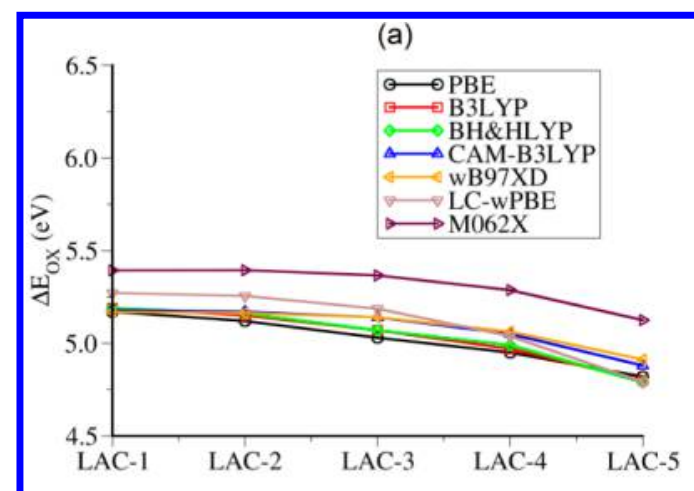

(c)

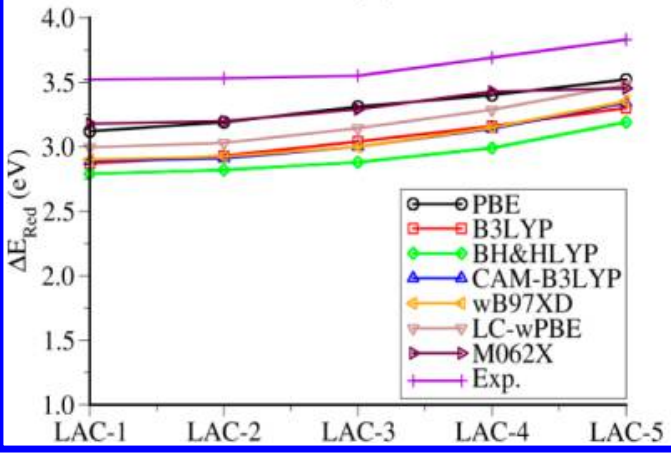

(b)

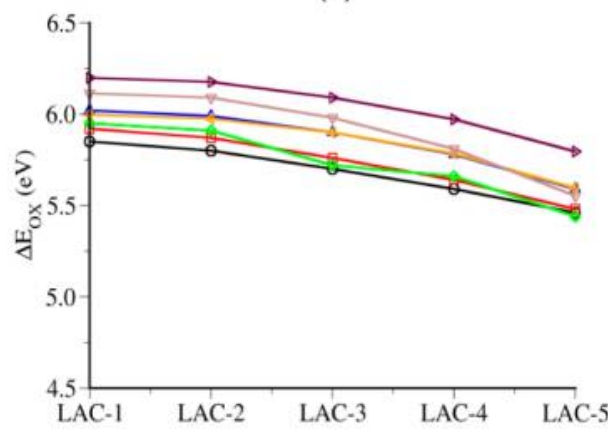

(d)

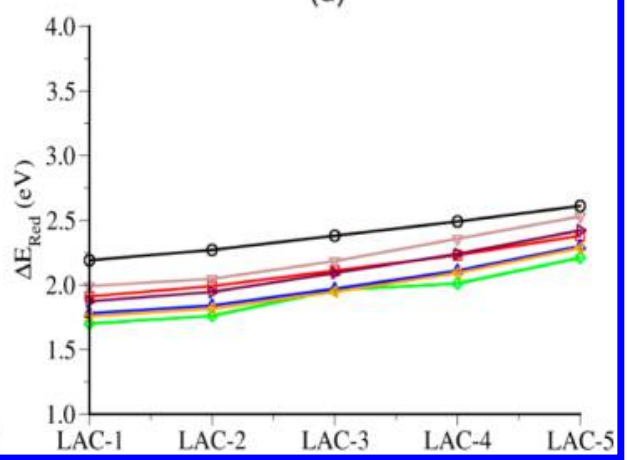

Figure 1. Computational $\Delta E_{\text {ox }}(\mathrm{eV})$ for the LAC dyes in THF solution (a) and in the gas phase (b). Experimental ${ }^{10}$ and computational $\Delta E_{\text {red }}(\mathrm{eV})$ for the LAC dyes in THF solution (c) and in the gas phase (d).

although underestimation was still observed in both cases (Figure 1c and Figure S3 in SI). The use of long-range corrected functionals (CAM-B3LYP, $\omega$ B97XD, LC- $\omega$ PBE) and other hybrid functionals (B3LYP, BH\&HLYP) enhance these types of underestimations. Such a systematic error may be correlated to the biased descriptions of the orbital levels using the chosen functional. In additioin, this derivation may also be caused by the fact that molecular vibrations and solvent reorganization were not taken in to account in the calculations. Thus, if the energyshift corrections are taken into account to compensate for such systematic errors, the B3LYP, BH\&HLYP, CAM-B3LYP, and $\omega \mathrm{B} 97 \mathrm{XD}$ functionals could also provide a good estimation of the GSRP.

Interestingly, the GSRP predicted by Koopman's Theorem at the PBE level seemed to agree well with the experimental value, with the largest deviation of $\sim 0.2 \mathrm{eV}$. The GSOP and GSRP estimated using Koopman's Theorem and other functionals were much higher and lower than their adiabatic counterparts $\left(\Delta E_{\text {ox }}\right.$ and $\left.\Delta E_{\text {red }}\right)$, respectively. Thus, the estimated values obtained using Koopman's Theorem should be carefully examined. These differences may arise from neglecting the electronic relaxation effects for charged species. Furthermore, both $\Delta E_{\mathrm{ox}}$ and $-\varepsilon_{\mathrm{HOMO}}$ (Table S2b in SI) as well as $\Delta E_{\text {red }}$ and $-\varepsilon_{\text {LUMO }}$ (Table S3 in SI) showed the same dependence on functionals.

For a perfect porphyrin system, the HOMO and HOMO-1 orbitals are degenerate due to symmetry. The same case is true for the LUMO and LUMO+1 orbitals, which gives two Q states $^{125}$ with the same excitation energies in the low-energy domain. However, the conjugated groups attached to the porphyrin system strongly influence the frontier orbitals of the porphyrin moiety. Thus, the HOMO-HOMO-1 energy gap becomes larger when the conjugation is increased, which should result in quite different excitation energies for the two $Q$ states of the LAC dyes (Figure 2, Figure S4, and Table S4 in SI). Because

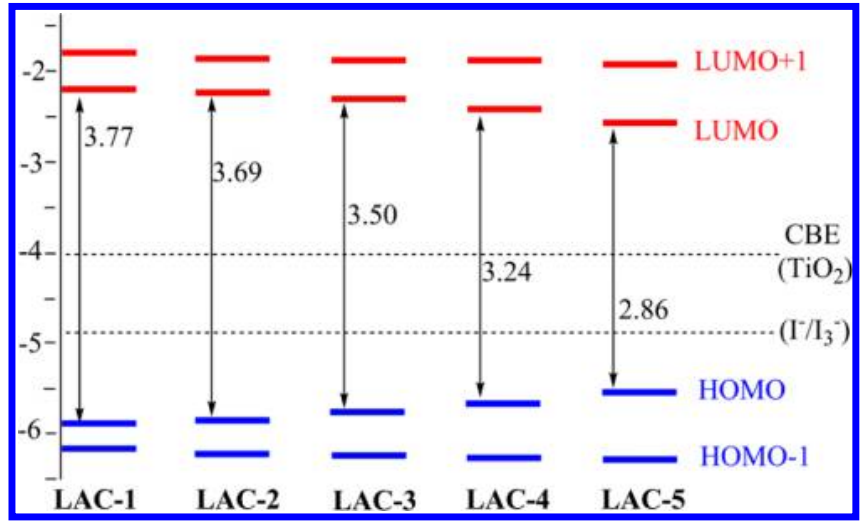

Figure 2. Computed MO levels and HOMO-LUMO gaps for LAC dyes at the BH\&HLYP/TZVP level. The horizontal dashed lines indicate the levels of the conduction band minimum (CBM) of the anatase $\mathrm{TiO}_{2}$ surface $(-4.0 \mathrm{eV})$ and the potential of $I^{-} / I_{3}^{-}(-4.8 \mathrm{eV})$ in the electrolyte solutions.

the Q-band absorption in the low-energy region should include the electronic transition of both $Q$ states, the separation of their excitation energies certainly caused the broadening of the absorption band in the long-wavelength domain.

For LAC dyes, the $S_{1}$ state is the optically bright state that is relevant to photoabsorption in the low-energy domain. Here, the calculated vertical excitation energies $\left(S_{1}\right)$ of the LAC dyes at the TDDFT levels were compared with the experimental values (Figure 3a and Table S5 in SI). As shown in Figures 3a and 3b, the best functional for estimating the vertical excitation energies was LC- $\omega$ PBE. In the solvent model (THF), we noticed that the negative ESOP values for all dyes were $0.52-1.21 \mathrm{eV}$ higher than the CBM values of $\mathrm{TiO}_{2}$. Moreover, a larger bias from the experimental value was predicted using the $\mathrm{PBE}$ and $\mathrm{BH} \& \mathrm{HLYP}$ 


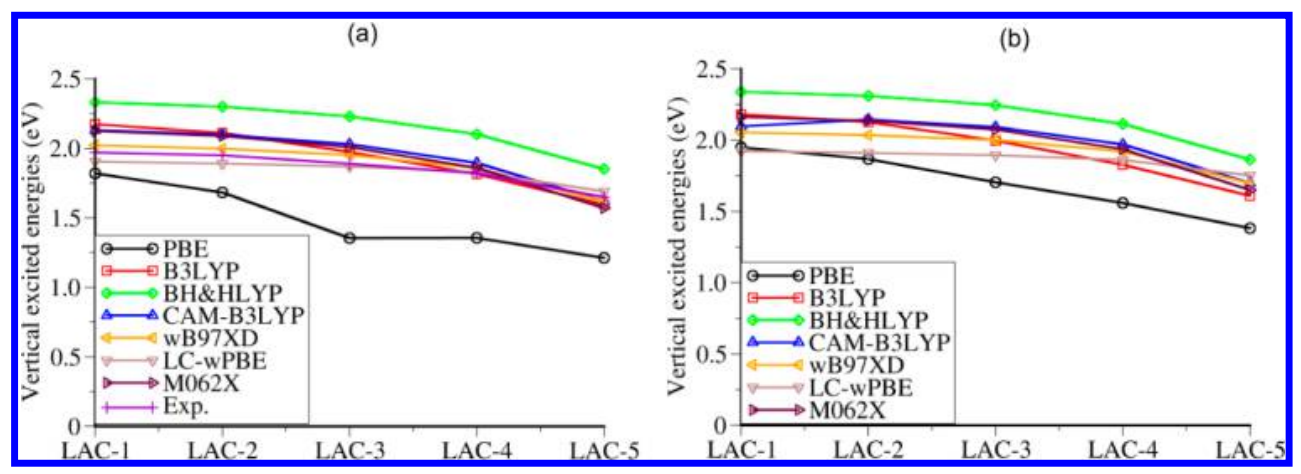

Figure 3. Experimental ${ }^{10}$ and computational vertical excitation energies (eV) for LAC dyes in THF solution (a) and in the gas phase (b).

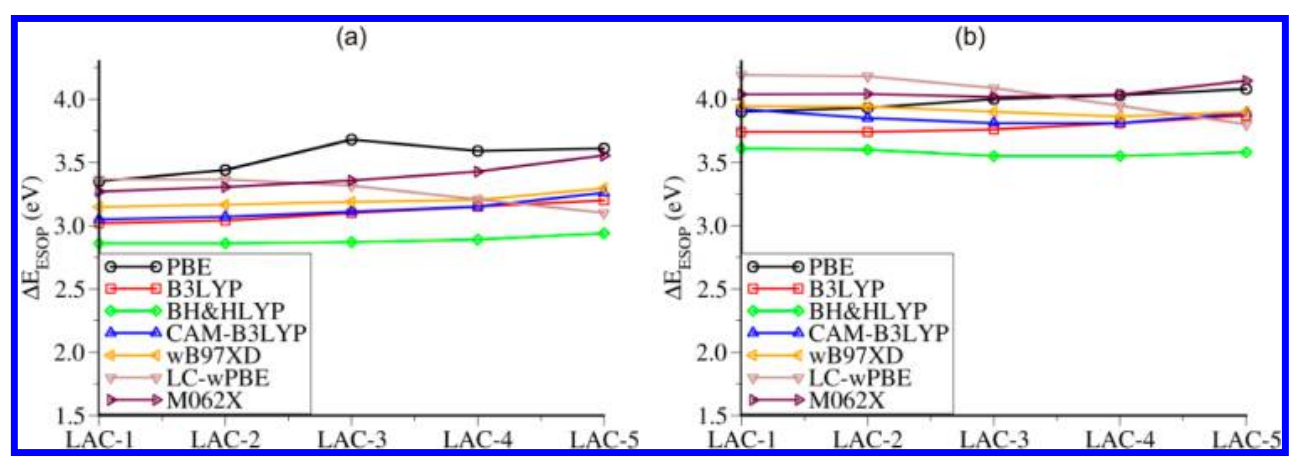

Figure 4. Computational ESOP (eV) for the LAC dyes in THF solution (a) and in the gas phase (b).

functionals. The other functionals (B3LYP, CAM-B3LYP, $\omega \mathrm{B} 97 \mathrm{XD}$, LC- $\omega \mathrm{PBE}$, and M062X) also systematically overestimated or underestimated the electronic transitions of the $S_{1}$ state for LAC dyes (Figure S5 in SI), which could be recovered by energy-shift corrections, as in the case of GSRP. Furthermore, the electronic character of the $S_{1}$ state was assigned to the $\mathrm{HOMO} \rightarrow$ LUMO transitions (Figure S6 in SI, about the MOs) regardless of the functional selection. Because the HOMO and LUMO energy gap deceased from LAC-1 to LAC-5 (Tables S2b and $\mathrm{S} 3$ in SI), the $S_{1}$ excitation energy also decreased significantly. The ESOP $\left(E^{\text {dye } *}\right)$ was estimated using eq 2 , which showed much weaker dependence on the conjugation size than GSOP and GSRP (Figure 4a,b, Table S6 in SI).

The current benchmark calculations for a series of acenemodified zinc-porphyrin sensitizers (LACs) indicated that the best method for depicting the reduction potentials was the first approach, $\Delta E_{\mathrm{red}}=\left(E^{0}-E^{-}\right)_{\mathrm{GS}}$, at the M06-2X level. By contrast, the LC- $\omega$ PBE functional gave rather reliable data in the estimation of excitation energies. This strongly indicates that the functional choice is highly system-specific, as suggested by De Angelis and others. ${ }^{14,88-90}$

In summary, the accuracy of the estimated parameters (i.e., GSOP and ESOP) is highly dependent on the choice of the DFT functional. Thus, the selection of suitable DFT functionals and the benchmark studies are critical for the reasonable descriptions of dye systems. Thanks to the error cancellation effects, one can also evaluate the systematic error of each functional and compensate for the systematic errors by using energy-shift corrections if no functional provides satisfactory data. In this way, more DFT functionals can be used to provide reasonable estimations of GSRP or ESOP.

It is not easy to find a specific LAC structure that shows the most desirable values of LHE, $\Delta G_{\text {inject }}$ and $\Delta \mathrm{CB}$. The balance of these parameters might be essential for achieving high performance. ${ }^{11,23}$ We also suggest that the flexibility of the dye molecule has a very important influence on its geometric and electronic properties.

In the MD simulation, the large distortion of the LAC molecule was observed (Figure 5a). This may have strongly affected the optoelectronic properties of the dyes. Further structural analyses were performed and are listed in the Supporting Information (Figure S7 and Table S7). The photoelectronic properties (i.e., the LHE and dipole moment $(\mu)$ ) were calculated at the TDDFT level from the snapshots (50 structures) along the trajectories. The order of the oscillator strength was successfully predicted as being larger for LAC-3 than for LAC-1, which was consistent with the experimental PCE order. The calculations based on the equilibrium geometries failed to predict the performance order between LAC-3 and LAC-5, which has been interpreted by a previous work to be the result of nonadiabatic processes in the LAC-5 dyes. ${ }^{10}$ However, our current study may provide an alternative and complementary explanation. The LHE values of LAC-3 seemed to be distributed more widely than the LHE values of LAC-1 and LAC-5, which could be attributed to the higher overall PCE efficiency of LAC-3 (Figure $5 b$ ). The dipole moment, which is related to the semiconductor conduction band shift $(\Delta \mathrm{CB})$, also indicated its varying contribution to the energy-conversion efficiency (Figure 5c). The absorption spectra of the LAC dyes were also calculated at the TDDFT/CAM-B3LYP/6-31G* levels based on snapshots from the dynamics trajectories (Figure $5 \mathrm{~d}$ ). The calculated and experimental spectra seemed to agree well in terms of their porphyrin-character absorption spectra, $\mathrm{B}$ and $\mathrm{Q}$ bands, and the relative intensities of their main spectral features. It is worth noting that the lowest-energy absorptions were relatively red-shifted. Although no conclusive results were obtained, some insights about the dynamic contribution of the flexibility of the dye molecule to its molecular geometries and orientation, which strongly affects the electronic structures of the dyes, were highlighted. This 


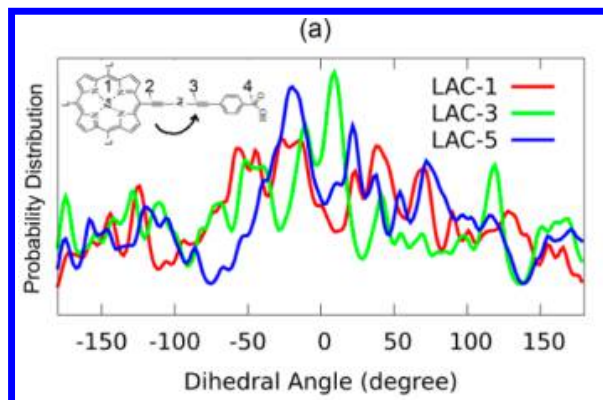

(c)

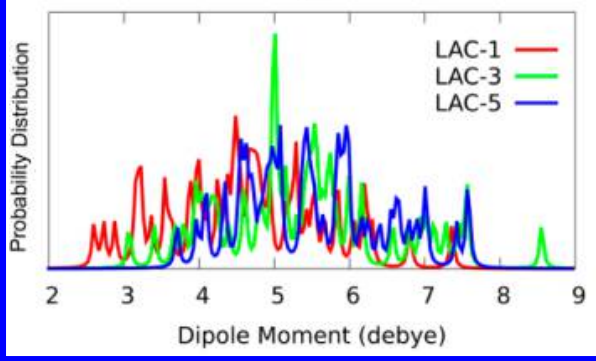

(b)

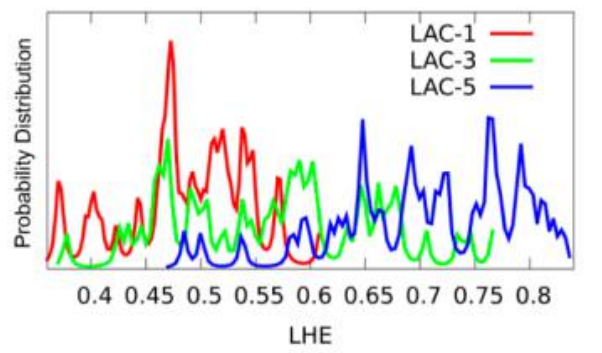

(d)

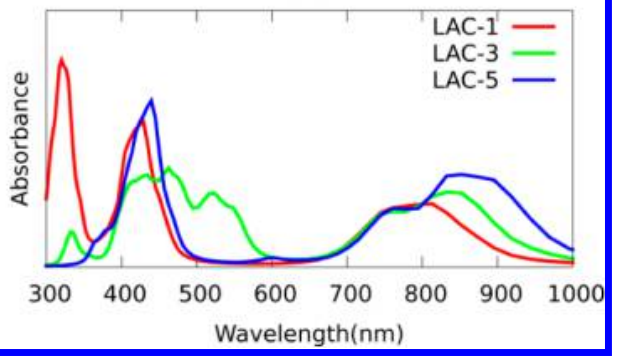

Figure 5. (a) Probability distribution of dihedral $\alpha$ ( $\angle 1234$, top left corner), where L is 2,4-ditert-butylphenyl. (b) Probability distribution of LHE. (c) Probability distribution of dipole moments. (d) UV-visible spectra of LAC-1, LAC-3, and LAC-5.

contribution should be considered in the design of dyes for use in DSSCs.

3.2. Dye@TiO 2 3.2.1. Cluster Models. To determine the trends of interaction between dyes containing acene groups of different sizes and the $\mathrm{TiO}_{2}$ substrate, LAC-1, LAC-3, and LAC-5 were calculated in order to investigate the structural and electronic properties of the dye@ $\mathrm{TiO}_{2}$ complex (Figure 6). Upon

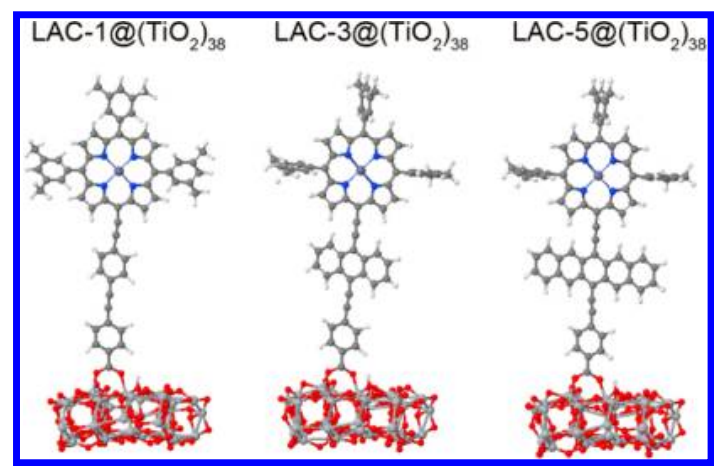

Figure 6. Optimized structure of the LAC-1@( $\left(\mathrm{TiO}_{2}\right)_{38}$, LAC$3 @\left(\mathrm{TiO}_{2}\right)_{38}$, and LAC-5@( $\left.\mathrm{TiO}_{2}\right)_{38}$ systems with the LAC dye adsorbed on the $\mathrm{TiO}_{2}(101)$ surface.

structural relaxation, the $\mathrm{Ti}-\mathrm{O}_{\text {dye }}$ bond distance decreased in the order of LAC-1, LAC-3, and LAC-5. The band gaps for the isolated dyes were in the order of LAC-1 > LAC-3 > LAC-5. This

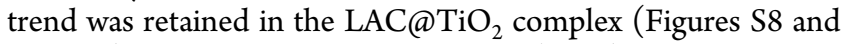
S9 in SI). Overall, the smaller LAC-1@ $\left(\mathrm{TiO}_{2}\right)_{38}$ and the larger LAC-5@ $\left(\mathrm{TiO}_{2}\right)_{38}$ clusters gave quite similar total DOS and PDOS (projected density of states) results compared to the LAC-3@ $\left(\mathrm{TiO}_{2}\right)_{38}$ cluster at different functional levels.

Because LAC-3 showed the best performance among all the LAC dyes, the LAC-3@ $\left(\mathrm{TiO}_{2}\right)_{38}$ system can reasonably be chosen as a representative dye for studying the electronic structures of dye@ $\mathrm{TiO}_{2}$ systems in general. For the LAC-3@ $\mathrm{TiO}_{2}$ complex, the bidentate bridging mode was more stable (by $0.94 \mathrm{eV}$ ) than the monodentate mode (Figure S10 in SI). Thus, only the bidentate bridging mode is reported in the following discussion. The most stable binding structure of the LAC$3 @\left(\mathrm{TiO}_{2}\right)_{38}$ cluster was that in which the dye was placed on the $\mathrm{TiO}_{2}$ surface in a bidentate-bridging mode, with one proton transferred to a nearby surface oxygen. The LAC-3 dye was adsorbed almost upright onto the $\mathrm{TiO}_{2}$ surface (Figure 6). A short binding distance $(<2.1 \AA)$ between the carboxylate anchoring group and the surface titanium atom indicated that the LAC-3 was firmly attached to the semiconductor surface. The similar binding mode of the dye@ $\mathrm{TiO}_{2}$ complex was also found in many previous reports. ${ }^{15,33,111,126-131}$

As shown in Figure 7, the DOS values of the LAC-3@ $\left(\mathrm{TiO}_{2}\right)_{38}$ complex, bare $\mathrm{TiO}_{2}$ and the isolated LAC-3 dye were obtained at the PBE/SVP, B3LYP/SVP, and BH\&HLYP/SVP levels. The total DOS of the LAC-3@( $\left.\mathrm{TiO}_{2}\right)_{38}$ complex was also projected onto the individual components. The predicted HOMOLUMO band gap of the bare $\mathrm{TiO}_{2}$ cluster was $2.5 \mathrm{eV}$ at the PBE/SVP level, which was smaller than the band gap of $3.2 \mathrm{eV}$ in the bulk $\mathrm{TiO}_{2}{ }^{112}$ As discussed by previous works, ${ }^{132}$ this underestimation of the energy gap comes from the local properties of pure GGA functionals. The predicted HOMO-LUMO band gap of $\mathrm{TiO}_{2}$ increased to $4.1 \mathrm{eV}$ at the B3LYP level (20\% HF exchange) and $6.9 \mathrm{eV}$ at the BH\&HLYP level (50\% $\mathrm{HF}$ exchange). A similar observation about the overestimation of the band gap has also been reported in previous CAM-B3LYP calculations by Liang and co-workers. ${ }^{15}$

For the LAC-3@( $\left.\mathrm{TiO}_{2}\right)_{38}$ complexes, the LAC dye absorption introduced several occupied orbitals into the HOMO-LUMO gap of the pure $\mathrm{TiO}_{2}$ nanoparticle. This decreased the computed band gap from $2.5 \mathrm{eV}$ ( pure $\mathrm{TiO}_{2}$ ) to $0.1 \mathrm{eV}\left(\right.$ dye $\left.@ \mathrm{TiO}_{2}\right)$ at the PBE/SVP level, $0.6 \mathrm{eV}$ at the B3LYP level, and $2.3 \mathrm{eV}$ at the $\mathrm{BH} \& H L Y P$ level. Although significant deviations were observed, the qualitative picture remained for all levels. In particular, the HOMO of the LAC-3@ $\left(\mathrm{TiO}_{2}\right)_{38}$ cluster is fully composed of the HOMO of the isolated LAC-3 dye (Figure 8), whereas the LUMO of the cluster corresponds to the CBM of the bare $\mathrm{TiO}_{2}$. Thus, no strong interaction existed between the HOMO of the LAC-3 dye and the orbitals of the $\mathrm{TiO}_{2}$ nanoparticle. In contrast, the PDOS of the virtual orbitals of the dye had strong overlaps 


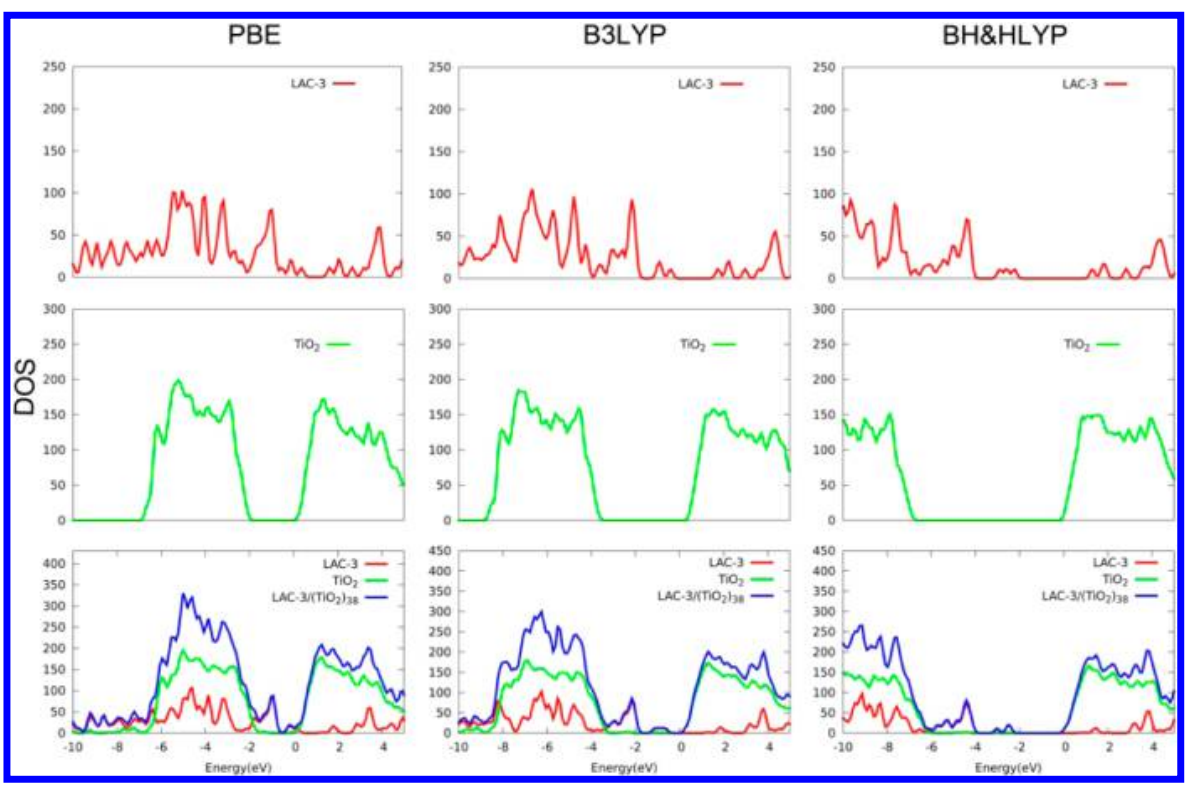

Figure 7. DOS and PDOS of LAC-3@ $\left(\mathrm{TiO}_{2}\right)_{38}$ at the PBE/SVP, B3LYP/SVP, and BH\&HLYP/SVP levels.

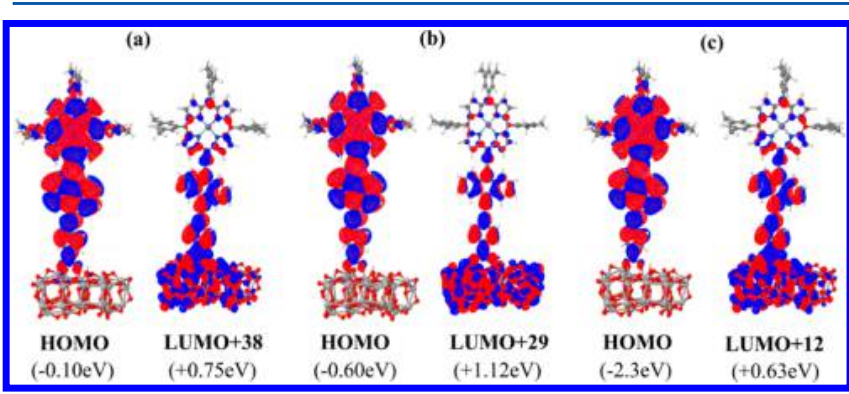

Figure 8. Plot of the HOMO and the first molecular orbital including the dye contribution. $\mathrm{LUMO}+38, \mathrm{LUMO}+29$, and LUMO+12 for LAC$3 @\left(\mathrm{TiO}_{2}\right)_{38}$ at the PBE/SVP (a), B3LYP/SVP (b), and BH\&HLYP/ SVP (c) levels.

with the PDOS of the conduction band of the $\mathrm{TiO}_{2}$ semiconductor at all levels, implying their strong interaction.

In the LAC-3@( $\left(\mathrm{TiO}_{2}\right)_{38}$ system, the first virtual orbital composed of significant contribution from dye is LUMO+41 (PBE), LUMO+37 (B3LYP), and LUMO+22 (BH\&HLYP), whose energy is closed to that of the LUMO of isolated dye. In principle, this virtual orbital is energetically accessible by visible light excitations of dyes, because the transitions from the HOMO of the cluster (mainly composed of HOMO of isolated dye) to it are $\sim 2 \mathrm{eV}$. However, between the LUMO and this virtual orbital, a few orbitals also display the delocalization feature over dye and $\mathrm{TiO}_{2}$, although the electron density located on the dye is too little to be visible in the DOS and PDOS in Figure 7. The first orbital including the dye contribution is LUMO+38 at the PBE level (Figure 8a), LUMO+29 at the B3LYP level (Figure 8b), and LUMO+12 at the BH\&HLYP level (Figure 8c).

In summary, we clearly conclude that the dye inserted its unoccupied LUMO deeply into the conduction band of $\mathrm{TiO}_{2}$, while no interaction existed between the $\mathrm{HOMO}$ of the dye and the valence band of $\mathrm{TiO}_{2}$.

It is clear that the efficient electron injection from the LAC-3 dye to $\mathrm{TiO} 2$ should take place after the photoexcitation of the LAC-3 dye. Here, the injection time from the dye to $\mathrm{TiO}_{2}$, as an important parameter of the electron transfer efficiency, was estimated using a simple model derived from the NewnsAnderson approach, which has been used successfully in previous studies. ${ }^{39,133,134}$ The predicted injection time scale was in the sub-50 fs regime no matter which functional is chosen, indicating that the efficient LAC-3 $\rightarrow \mathrm{TiO}_{2}$ electron transfer should take place. To address the impact of the cluster sizes of the $\mathrm{TiO}_{2}$ nanocrystals, a larger anatase cluster $\left(\mathrm{TiO}_{2}\right)_{68}$ was also employed in the analysis of the electronic structure of the dye@ $\mathrm{TiO}_{2}$ systems (Figure S11 in SI). At the PBE/SVP level, the larger LAC@ $\left(\mathrm{TiO}_{2}\right)_{68}$ cluster gave consistent total DOS and PDOS results comparable to the smaller LAC-3@ $\left(\mathrm{TiO}_{2}\right)_{38}$ cluster (Figure $\mathrm{S} 12$ In SI). Because more atoms were included in $\left(\mathrm{TiO}_{2}\right)_{68}$, the contribution of $\mathrm{TiO}_{2}$ to the total DOS increased, whereas the profile of each PDOS (LAC-3 dye and $\mathrm{TiO}_{2}$ ) seemed to be independent of the cluster size. Thus, the $\left(\mathrm{TiO}_{2}\right)_{38}$ model was sufficient in this work.

3.2.2. Periodic Model. The periodic calculations on the surface slab models were further conducted to study the LAC$3 @ \mathrm{TiO}_{2}$ interactions. The equilibrium geometry of the LAC-3@ $\mathrm{TiO}_{2}$ complex is presented in Figure 9. Both the cluster and periodic models gave similar connection patterns between the LAC-3 dye and the $\mathrm{TiO}_{2}$ surface, while the top layer of the $\mathrm{TiO}_{2}$ surface displayed less distortion due to the periodic constraint.

The DOS of the LAC-3@ $@ \mathrm{TiO}_{2}$ (101) system as well as the PDOS values of the LAC- 3 dye and $\mathrm{TiO}_{2}$ are presented in Figure 10. The DOS values of the isolated LAC-3 dye and the bare $\mathrm{TiO}_{2}$ are shown in Figures S13 and S14 in SI. Similar to the cluster model, a band gap of $\sim 2.0 \mathrm{eV}$ was observed for bare $\mathrm{TiO}_{2}$ in the periodic model at the PBE level. The PDOS ratio (dye/ $\mathrm{TiO}_{2}$ ) decreased obviously in the order of small clusters to large clusters to a period system, which was due to the inclusion of more atoms in $\mathrm{TiO}_{2}$. The PDOS patterns, by contrast, remained similar. Basically, the HOMO of the complex was only composed of the HOMO of the LAC-3 dye. Significant couplings were observed between the LUMO of the dye and the conduction band of the $\mathrm{TiO}_{2}$. These findings also indicated that the efficient electron transfer from the dye to $\mathrm{TiO}_{2}$ should have occurred after photo excitation.

It is well-known that DFT may only provide a preliminary understanding of the electronic structure of the dye@ $\mathrm{TiO}_{2}$ interface. $^{135,136}$ As shown in Figure 7 , an increase in the HF exchange led to the enhancement of the energy gap between the 


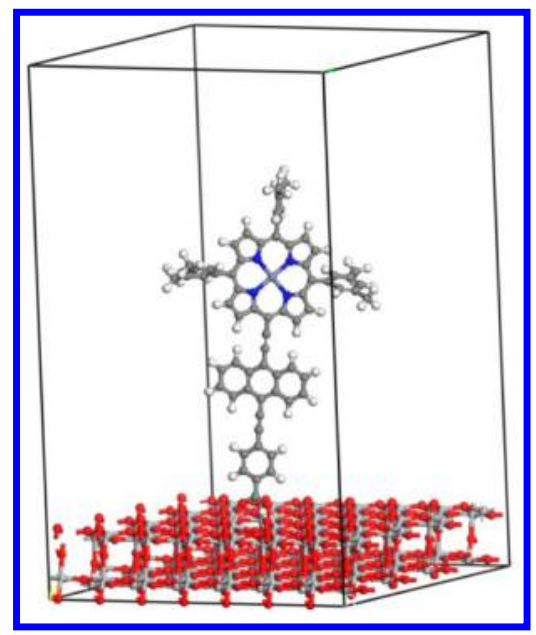

Figure 9. Optimized structure of the LAC-3@ $\mathrm{TiO}_{2}$ system within a periodic model.

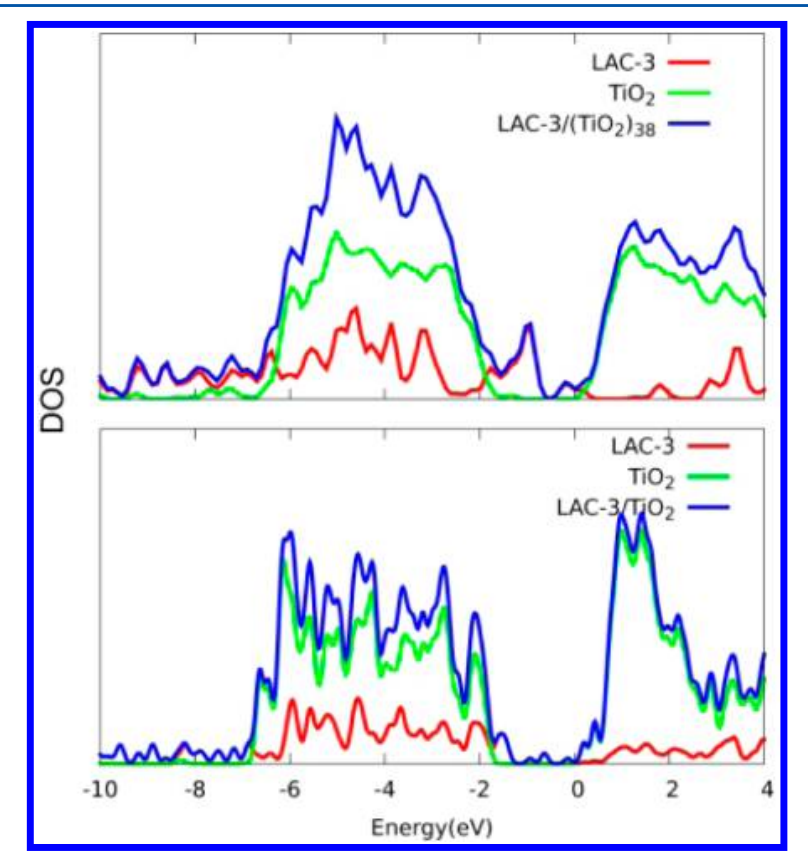

Figure 10. DOS and PDOS of the LAC-3@ $\mathrm{TiO}_{2}$ complex system within the periodic (lower panel) and cluster models (upper panel).

$\mathrm{HOMO}$ of the dyes and the $\mathrm{CBM}$ of $\mathrm{TiO}_{2}$, indicating the nonsynchronic shifts of orbital levels for the dye and $\mathrm{TiO}_{2}$. In this case, it was difficult to obtain the precise band gap and band alignment between $\mathrm{TiO}_{2}$ and the dye due to its strong dependence on the functional selection. Thus, it is still very important to develop effective and accurate theoretical methods to solve this problem. In addition, the correct description of the photoreaction should include the excited state of the whole dye@ $\mathrm{TiO}_{2}$ complex system. Hopefully, such calculations may become possible in the near future with the development of TDDFT, high-level electron-correlated methods and the GW-BSE method.

\section{DISCUSSION}

It is well-known that theoretical screening and designing studies of DSSCs demand fast and accurate electronic methods. Currently, many theoretical works have employed the standard DFT calculations on dyes, providing valuable results that have helped experimentalists to design novel dyes. Nonetheless, it is still very important to improve the accuracy of theoretical prediction. To achieve this goal, some preliminary knowledge on theoretical modeling, particularly its advantages and limitations, should be accumulated. Because the current work makes considerable effort to check the performance of different methods, some physical insights and general rules can be suggested here, which may promote the future design of novel dyes for use in DSSCs.

(1) Due to its good trade-off between computational costs and accuracy, the DFT method may be one of the most widely used approaches for calculating the energies and properties of large molecular systems such as dye@ $\mathrm{TiO}_{2}$ (a few hundred atoms). ${ }^{14,15,22,23,25,120,137}$ In addition, the assessment of $\mathrm{xc}$ functionals is a very important issue in the theoretical modeling of DSSCs. Most importantly, the selection of the $\mathrm{xc}$ functional with the best performance seems to be highly dependent on the specific system. However, it is very critical to select suitable DFT functionals and evaluate their performances in order to obtain a reasonable description of the dye system. The reason is obvious: the computational accuracy, somehow, is highly dependent on the choice of the DFT functional. According to the current work, we suggest two reasonable ways of obtaining a precise estimation of the relevant parameters. First, a benchmark should be used in which careful and systematic calculations are used to identify a functional with better performance. Second, error cancellation may be considered, in which the systematic error of each functional is evaluated and additional energyshift corrections are made to compensate for the systematic error if no functional gives satisfactory data.

(2) In predicting the GSRP or GSOP, the Koopman's Theorem is highly dependent on functionals, which indicates the instability of this approach. Thus, the results obtained from this method should be carefully examined.

(3) The influence of structural flexibility of the dye molecule should not be ignored. This feature has been largely neglected in past theoretical works, and only recently the strong effects of thermal fluctuations on the structural and optical properties of dye molecules have been discussed. $^{25,51}$ Our MD-TDDFT combined approaches indicates that the flexibility of the isolated dye causes pronounced fluctuation in the LHE, dipole moment $(\mu)$ excited state energies, and so on. Although it is not conclusive that the dynamic fluctuations of the isolated dyes may strongly affect the electronic structures of the LAC dyes, this feature nevertheless should be considered in the future design of efficient dyes for DSSCs.

(4) Many studies have used the cluster or periodic model to model dye@semiconductor interfaces. However, the key question is "which model is more suitable?" Our calculations indicate that both the cluster and periodic models behave similarly in the simulating the dye@ $\mathrm{TiO}_{2}$ complex. The larger dye@ $\left(\mathrm{TiO}_{2}\right)_{68}$ cluster, smaller dye@ $\left(\mathrm{TiO}_{2}\right)_{38}$ cluster, and the LAC dye on the $\mathrm{TiO}_{2}$ slab gave quite similar orbital alignments, DOS, and PDOS results, except for the differences in the PDOS intensities. This indicates that the results are not very sensitive to the size of the $\mathrm{TiO}_{2}$ cluster. The dye@ $\left(\mathrm{TiO}_{2}\right)_{38}$ cluster should be a reasonable model to mimic the dye- $\mathrm{TiO}_{2}$ interactions. In fact, the difference caused by the cluster/periodic model or cluster size is much less than the bias introduced by the DFT 
functional, again showing the critical role of the latter option.

(5) The injection times from the dye to $\mathrm{TiO}_{2}$ can be estimated using the simple Newns-Anderson approach. For instance, the predicted injection time is less than $50 \mathrm{fs}$. This time scale seems to be consistent with the ones derived from more rigorous treatments using various recently developed methods, such as those using electronic dynamics, semiclassical dynamics, and full quantum dynamics. Considering the simplicity and reasonability of the NewnsAnderson method, it can be used as a cheap approach for estimating the injection times from the dye to $\mathrm{TiO}_{2}$ in the theoretical screening studies of dyes, at least in a qualitative manner.

Even when all the issues mentioned above are carefully considered, the theoretically designed dyes still might not consider all points. For example, in this work, the nonadiabatic decay was not taken into account, which may explain why the LAC-5 was not the best choice even though the rough computation seemed to predict its excellence. Thus, it is also very important to obtain more information from experimental studies. In this sense, the future design of effective dyes molecules may require the further combination of experimental and theoretical works. A feed-back approach between theoretical calculations and experimental observations should be constructed for the efficient design of novel dyes.

\section{CONCLUSIONS}

In this work, we examined the performance of various theoretical methods in the modeling of zinc-porphyrinacene-modified LAC dyes as photosensitizers in DSSCs. For the dye@semiconductor

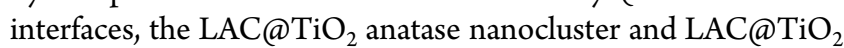
periodic system were used to investigate the electronic structure of the dye@ $\mathrm{TiO}_{2}$ complex.

Based on a comparison with available results, we provided some commentaries and proposed a few rules for modeling DSSCs. For instance, DFT functionals should be carefully selected in the design of dyes. The use of energy shift may be a practical option to achieve systematic error cancellation. Current benchmark calculations for a series of acene-modified zincporphyrin sensitizers (LAC) indicated that M06-2X xc functional based on the equation of $\Delta E_{\text {red }}=\left(E^{0}-E^{-}\right)_{\mathrm{Gs}}$ provided the best approach for depicting the reduction potentials, whereas the LC$\omega \mathrm{PBE} \times \mathrm{xc}$ functional was the best computational choice for computing the excitation energies. The influence of the structural flexibility on the dye molecules should not be neglected, as indicated by De Angelis et al. ${ }^{51,106}$ Both the cluster and periodic models provided similar behaviors in the simulation of the dye@ $\mathrm{TiO}_{2}$ complex. A simple model derived from the NewnsAnderson approach could be used to roughly reproduce the ultrafast time scale of electron injection (sub-50 fs) from the dye to $\mathrm{TiO}_{2}$. Thus, by considering all issues described above, reasonable results may be achieved at the qualitative level.

However, the precise treatment of photoinduced dynamics in dye@ $\mathrm{TiO}_{2}$ systems is still far from sufficient due to the system complexity, the deficiency of excited-state electronic-structure methods and the difficulty of the real-time electron-injection simulation. This topic therefore presents a great challenge to theoretical chemistry in the future.

\section{ASSOCIATED CONTENT}

\section{S Supporting Information}

Detailed photophysical and electrochemical values for the ground-state and excited-state features of isolated dyes calculated with different $\mathrm{xc}$-functionals in THF solution and in the gas phase; the alignment between the frontier orbitals of LAC dyes and those of $\mathrm{TiO}_{2}$; the initial configuration obtained by randomly positioning the LAC and THF molecules within a cubic box; the optimized single-bridge structure of the LAC-3@( $\left.\mathrm{TiO}_{2}\right)_{38}$ and the structure of LAC-3@( $\left(\mathrm{TiO}_{2}\right)_{68}$; and the DOS (PDOS) of differently sized LAC@TiO 2 at the PBE/SVP, B3LYP/SVP and $\mathrm{BH} \& H L Y P / S V P$ levels. This material is available free of charge via the Internet at http://pubs.acs.org.

\section{AUTHOR INFORMATION}

\section{Corresponding Authors}

*Fax: +86-551-3602832. Tel.: +86-551-3602832. E-mail: zhaojin@ustc.edu.cn.

*Fax: +86-532-80662778. Tel.: +86-532-80662630. E-mail: lanzg@qibebt.ac.cn.

\section{Notes}

The authors declare no competing financial interest.

\section{ACKNOWLEDGMENTS}

Financial support was provided by the special foundation of PostDoctoral Innovation Projects of Shandong Province, the CAS 100 Talent Project, the National Science Foundation of China (Grant Nos. 11322434, 91233106, and 21303238), and the Key Lab of Nanodevices and Nanoapplications, CAS (Grant No. 14HZ03). The authors also thank the Supercomputing Center, the Computer Network Information Center, CAS, the National Supercomputing Center in Shenzhen and the Super Computational Center of CAS-QIBEBT for providing computational resources.

\section{REFERENCES}

(1) O’Regan, B.; Grätzel, M. A Low-Cost, High-Efficiency Solar Cell Based On Dye-Sensitized Colloidal $\mathrm{TiO}_{2}$ Films. Nature 1991, 353, 737740.

(2) Grätzel, M. Photoelectrochemical Cells. Nature 2001, 414, 338344.

(3) Li, L.-L.; Diau, E. W.-G. Porphyrin-Sensitized Solar Cells. Chem. Soc. Rev. 2013, 42, 291-304.

(4) Hagfeldt, A.; Boschloo, G.; Sun, L.; Kloo, L.; Pettersson, H. DyeSensitized Solar Cells. Chem. Rev. 2010, 110, 6595-6663.

(5) Nazeeruddin, M. K.; De Angelis, F.; Fantacci, S.; Selloni, A.; Viscardi, G.; Liska, P.; Ito, S.; Takeru, B.; Grätzel, M. Combined Experimental and DFT-TDDFT Computational Study of Photoelectrochemical Cell Ruthenium Sensitizers. J. Am. Chem. Soc. 2005, 127, 16835-16847.

(6) Wang, Q.; Ito, S.; Grätzel, M.; Fabregat-Santiago, F.; Mora-Seró, I.; Bisquert, J.; Bessho, T.; Imai, H. Characteristics of High Efficiency DyeSensitized Solar Cells. J. Phys. Chem. B 2006, 110, 25210-25221.

(7) Grätzel, M. Recent Advances in Sensitized Mesoscopic Solar Cells. Acc. Chem. Res. 2009, 42, 1788-1798.

(8) Kakiage, K.; Aoyama, Y.; Yano, T.; Otsuka, T.; Kyomen, T.; Unno, M.; Hanaya, M. An Achievement of over 12 Percent Efficiency in an Organic Dye-Sensitized Solar Cell. Chem. Commun. 2014, 50, 6379-6381.

(9) Mathew, S.; Yella, A.; Gao, P.; Humphry-Baker, R.; CurchodBasile, F. E.; Ashari-Astani, N.; Tavernelli, I.; Rothlisberger, U.; NazeeruddinMd, K.; Grätzel, M. Dye-Sensitized Solar Cells with 13\% Efficiency Achieved Through the Molecular Engineering of Porphyrin Sensitizers. Nat. Chem. 2014, 6, 242-247.

(10) Lin, C.-Y.; Wang, Y.-C.; Hsu, S.-J.; Lo, C.-F.; Diau, E. W.-G. Preparation and Spectral, Electrochemical, and Photovoltaic Properties 
of Acene-Modified Zinc Porphyrins. J. Phys. Chem. C 2009, 114, 687693.

(11) Fan, W.; Tan, D.; Deng, W.-Q. Acene-Modified Triphenylamine Dyes for Dye-Sensitized Solar Cells: A Computational Study. ChemPhysChem 2012, 13, 2051-2060.

(12) Kalyanasundaram, K.; Grätzel, M. Applications of Functionalized Transition Metal Complexes in Photonic and Optoelectronic Devices. Coord. Chem. Rev. 1998, 177, 347-414.

(13) Yang, L.-N.; Sun, Z.-Z.; Chen, S.-L.; Li, Z.-S. Iodinated Al ${ }^{\mathrm{III}}$-Based Phthalocyanines are Promising Sensitizers for Dye-Sensitized Solar Cells; A Theoretical Comparison Between $\mathrm{Zn}^{\mathrm{II}}, \mathrm{Mg}^{\mathrm{II}}$, and $\mathrm{Al}^{\mathrm{III}}$-Based Phthalocyanine Sensitizers. ChemPhysChem 2014, 15, 458-466.

(14) Pastore, M.; Fantacci, S.; De Angelis, F. Modeling Excited States and Alignment of Energy Levels in Dye-Sensitized Solar Cells: Successes, Failures, and Challenges. J. Phys. Chem. C 2013, 117, 3685-3700.

(15) Ju, M.-G.; Liang, W. Computational Insight on the Working Principles of Zinc Porphyrin Dye-Sensitized Solar Cells. J. Phys. Chem. C 2013, 117, 14899-14911.

(16) Liang, J.; Zhu, C.; Cao, Z. Electronic and Optical Properties of the Triphenylamine-Based Organic Dye Sensitized $\mathrm{TiO}_{2}$ Semiconductor: Insight from First Principles Calculations. Phys. Chem. Chem. Phys. 2013, 15, 13844-13851.

(17) Yang, L.-N.; Sun, Z.-Z.; Li, Q.-S.; Chen, S.-L.; Li, Z.-S.; Niehaus, T. A. Unsymmetrical Squaraine Dye Containing Dithieno[3,2-b:2',3'd]Pyrrole as a П-Spacer: A Potential Photosensitizer for Dye-Sensitized Solar Cells. J. Power Sources 2014, 268, 137-145.

(18) $\mathrm{Si}, \mathrm{L}$.; $\mathrm{He}, \mathrm{H}$. Porphyrin Dyes on $\mathrm{TiO}_{2}$ Surface with Different Orientations: A Photophysical, Photovoltaic and Theoretical Investigation. J. Phys. Chem. A 2014, 118, 3410-3418.

(19) Santhanamoorthi, N.; Lo, C.-M.; Jiang, J.-C. Molecular Design of Porphyrins for Dye-Sensitized Solar Cells: A DFT/TDDFT Study. J. Phys. Chem. Lett. 2013, 4, 524-530.

(20) Orbelli Biroli, A.; Tessore, F.; Pizzotti, M.; Biaggi, C.; Ugo, R.; Caramori, S.; Aliprandi, A.; Bignozzi, C. A.; De Angelis, F.; Giorgi, G.; et al. A Multitechnique Physicochemical Investigation of Various Factors Controlling the Photoaction Spectra and of Some Aspects of the Electron Transfer for a Series of Push-Pull Zn(II) Porphyrins Acting as Dyes in DSSCs. J. Phys. Chem. C 2011, 115, 23170-23182.

(21) Lee, C.-W.; Lu, H.-P.; Lan, C.-M.; Huang, Y.-L.; Liang, Y.-R.; Yen, W.-N.; Liu, Y.-C.; Lin, Y.-S.; Diau, E. W.-G.; Yeh, C.-Y. Novel Zinc Porphyrin Sensitizers for Dye-Sensitized Solar Cells: Synthesis and Spectral, Electrochemical, and Photovoltaic Properties. Chem.-Eur. J. 2009, 15, 1403-1412.

(22) Meng, S.; Kaxiras, E.; Nazeeruddin, M. K.; Grätzel, M. Design of Dye Acceptors for Photovoltaics from First-Principles Calculations. J. Phys. Chem. C 2011, 115, 9276-9282.

(23) Feng, J.; Jiao, Y.; Ma, W.; Nazeeruddin, M. K.; Grätzel, M.; Meng, S. First Principles Design of Dye Molecules with Ullazine Donor for Dye Sensitized Solar Cells. J. Phys. Chem. C 2013, 117, 3772-3778.

(24) Guillemoles, J.-F.; Barone, V.; Joubert, L.; Adamo, C. A Theoretical Investigation of the Ground and Excited States of Selected $\mathrm{Ru}$ and Os Polypyridyl Molecular Dyes. J. Phys. Chem. A 2002, 106, 11354-11360.

(25) Pastore, M.; De Angelis, F. Intermolecular Interactions in DyeSensitized Solar Cells: A Computational Modeling Perspective. J. Phys. Chem. Lett. 2013, 4, 956-974.

(26) Rekhis, M.; Labat, F.; Ouamerali, O.; Ciofini, I.; Adamo, C. Theoretical Analysis of the Electronic Properties of N3 Derivatives. J. Phys. Chem. A 2007, 111, 13106-13111.

(27) Hazebroucq, S.; Labat, F.; Lincot, D.; Adamo, C. Theoretical Insights on the Electronic Properties of Eosin Y, an Organic Dye for Photovoltaic Applications. J. Phys. Chem. A 2008, 112, 7264-7270.

(28) Perpéte, E. A.; Maurel, F.; Jacquemin, D. TD-DFT Investigation of Diarylethene Dyes with Cyclopentene, Dihydrothiophene, and Dihydropyrrole Bridges. J. Phys. Chem. A 2007, 111, 5528-5535.

(29) Preat, J.; Jacquemin, D.; Vercauteren, D.; Perpéte, E. A Quantitative Prediction of the Electronic Spectra of Thiocarbonyl
Chromophores: TD-DFT Versus SAC-CI. Theor. Chem. Acc. 2008, 119, 463-468.

(30) De Angelis, F.; Tilocca, A.; Selloni, A. Time-Dependent DFT Study of $\left[\mathrm{Fe}(\mathrm{CN})_{6}\right]^{4-}$ Sensitization of $\mathrm{TiO}_{2}$ Nanoparticles. J. Am. Chem. Soc. 2004, 126, 15024-15025.

(31) Wu, N.; Wang, J.; Tafen, D. N.; Wang, H.; Zheng, J.-G.; Lewis, J. P.; Liu, X.; Leonard, S. S.; Manivannan, A. Shape-Enhanced Photocatalytic Activity of Single-Crystalline Anatase $\mathrm{TiO}_{2}$ (101) Nanobelts. J. Am. Chem. Soc. 2010, 132, 6679-6685.

(32) Aradi, B.; Deák, P.; Huy, H. A.; Rosenauer, A.; Frauenheim, T. Role of Symmetry in the Stability and Electronic Structure of Titanium Dioxide Nanowires. J. Phys. Chem. C 2011, 115, 18494-18499.

(33) Pastore, M.; De Angelis, F. Aggregation of Organic Dyes on $\mathrm{TiO}_{2}$ in Dye-Sensitized Solar Cells Models: An ab Initio Investigation. ACS Nano 2010, 4, 556-562.

(34) Duncan, W. R.; Prezhdo, O. V. Temperature Independence of the Photoinduced Electron Injection in Dye-Sensitized $\mathrm{TiO}_{2}$ Rationalized by Ab Initio Time-Domain Density Functional Theory. J. Am. Chem. Soc. 2008, 130, 9756-9762.

(35) Meng, S.; Kaxiras, E. Electron and Hole Dynamics in DyeSensitized Solar Cells: Influencing Factors and Systematic Trends. Nano Lett. 2010, 10, 1238-1247.

(36) Negre, C. F. A.; Milot, R. L.; Martini, L. A.; Ding, W.; Crabtree, R. H.; Schmuttenmaer, C. A.; Batista, V. S. Efficiency of Interfacial Electron Transfer from Zn-Porphyrin Dyes into $\mathrm{TiO}_{2}$ Correlated to the Linker Single Molecule Conductance. J. Phys. Chem. C 2013, 117, 2446224470.

(37) De Angelis, F.; Fantacci, S.; Selloni, A.; Grätzel, M.; Nazeeruddin, M. K. Influence of the Sensitizer Adsorption Mode on the Open-Circuit Potential of Dye-Sensitized Solar Cells. Nano Lett. 2007, 7, 3189-3195.

(38) De Angelis, F.; Fantacci, S.; Selloni, A.; Nazeeruddin, M. K.; Grätzel, M. First-Principles Modeling of the Adsorption Geometry and Electronic Structure of $\mathrm{Ru}(\mathrm{II})$ Dyes on Extended $\mathrm{TiO}_{2}$ Substrates for Dye-Sensitized Solar Cell Applications. J. Phys. Chem. C 2010, 114, 6054-6061.

(39) Labat, F.; Ciofini, I.; Hratchian, H. P.; Frisch, M. J.; Raghavachari, K.; Adamo, C. Insights into Working Principles of Ruthenium Polypyridyl Dye-Sensitized Solar Cells from First Principles Modeling. J. Phys. Chem. C 2011, 115, 4297-4306.

(40) Abuabara, S. G.; Rego, L. G. C.; Batista, V. S. Influence of Thermal Fluctuations on Interfacial Electron Transfer in Functionalized $\mathrm{TiO}_{2}$ Semiconductors. J. Am. Chem. Soc. 2005, 127, 18234-18242.

(41) Persson, P.; Lundqvist, M. J. Calculated Structural and Electronic Interactions of the Ruthenium Dye N3 with a Titanium Dioxide Nanocrystal. J. Phys. Chem. B 2005, 109, 11918-11924.

(42) Labat, F.; Ciofini, I.; Hratchian, H. P.; Frisch, M.; Raghavachari, K.; Adamo, C. First Principles Modeling of Eosin-Loaded ZnO Films: A Step toward the Understanding of Dye-Sensitized Solar Cell Performances. J. Am. Chem. Soc. 2009, 131, 14290-14298.

(43) Mosconi, E.; Selloni, A.; De Angelis, F. Solvent Effects on the Adsorption Geometry and Electronic Structure of Dye-Sensitized $\mathrm{TiO}_{2}$ : A First-Principles Investigation. J. Phys. Chem. C 2012, 116, 5932-5940.

(44) De Angelis, F.; Fantacci, S.; Selloni, A. Time-Dependent Density Functional Theory Study of the Absorption Spectrum of $\left[\mathrm{Ru}\left(4,4^{\prime}\right.\right.$ $\mathrm{COOH}-2,2^{\prime}$-bpy $\left.)_{2}(\mathrm{NCS})_{2}\right]$ in Water Solution: Influence of the $\mathrm{pH}$. Chem. Phys. Lett. 2004, 389, 204-208.

(45) De Angelis, F.; Fantacci, S.; Selloni, A.; Nazeeruddin, M. K. Time Dependent Density Functional Theory Study of the Absorption Spectrum of the $\left[\mathrm{Ru}\left(4,4^{\prime}-\mathrm{COO}^{-}-2,2^{\prime}-\text { bpy }\right)_{2}(\mathrm{X})_{2}\right]^{4}(\mathrm{X}=\mathrm{NCS}, \mathrm{Cl})$ Dyes in Water Solution. Chem. Phys. Lett. 2005, 415, 115-120.

(46) De Angelis, F.; Fantacci, S.; Selloni, A.; Nazeeruddin, M. K.; Grätzel, M. Time-Dependent Density Functional Theory Investigations on the Excited States of $\mathrm{Ru}$ (II)-Dye-Sensitized $\mathrm{TiO}_{2}$ Nanoparticles: The Role of Sensitizer Protonation. J. Am. Chem. Soc. 2007, 129, 1415614157.

(47) De Angelis, F.; Fantacci, S.; Selloni, A. Alignment of the Dye's Molecular Levels with the $\mathrm{TiO}_{2}$ Band Edges in Dye-Sensitized Solar Cells: A DFT-TDDFT Study. Nanotechnology 2008, 19, 424002. 
(48) De Angelis, F. Direct vs Indirect Injection Mechanisms in Perylene Dye-Sensitized Solar Cells: A DFT/TDDFT Investigation. Chem. Phys. Lett. 2010, 493, 323-327.

(49) De Angelis, F.; Fantacci, S.; Mosconi, E.; Nazeeruddin, M. K.; Grätzel, M. Absorption Spectra and Excited State Energy Levels of the N719 Dye on $\mathrm{TiO}_{2}$ in Dye-Sensitized Solar Cell Models. J. Phys. Chem. C 2011, 115, 8825-8831.

(50) Selvaraj, A.; Hayase, S. Molecular Dynamics Simulations on the Aggregation Behavior of Indole Type Organic Dye Molecules in DyeSensitized Solar Cells. J. Mol. Model. 2012, 18, 2099-2104.

(51) Gebauer, R; De Angelis, F. A Combined Molecular Dynamics and Computational Spectroscopy Study of a Dye-Sensitized Solar Cell. New J. Phys. 2011, 13, 085013.

(52) Gupta, K. S. V.; Zhang, J.; Marotta, G.; Reddy, M. A.; Singh, S. P.; Islam, A.; Han, L.; De Angelis, F.; Chandrasekharam, M.; Pastore, M. Effect of the Anchoring Group in the Performance of CarbazolePhenothiazine Dyads for Dye-Sensitized Solar Cells. Dyes Pigm. 2015, $113,536-545$.

(53) Li, Z.; Zhang, X.; Lu, G. Electron Dynamics in Dye-Sensitized Solar Cells: Effects of Surface Terminations and Defects. J. Phys. Chem. B 2010, 114, 17077-17083.

(54) Vaissier, V.; Mosconi, E.; Moia, D.; Pastore, M.; Frost, J. M.; De Angelis, F.; Barnes, P. R. F.; Nelson, J. Effect of Molecular Fluctuations on Hole Diffusion within Dye Monolayers. Chem. Mater. 2014, 26, 4731-4740.

(55) Prezhdo, O. V.; Duncan, W. R.; Prezhdo, V. V. Photoinduced Electron Dynamics at the Chromophore-Semiconductor Interface: A Time-Domain Ab Initio Perspective. Prog. Surf. Sci. 2009, 84, 30-68.

(56) Chapman, C. T.; Liang, W.; Li, X. Ultrafast Coherent ElectronHole Separation Dynamics in a Fullerene Derivative. J. Phys. Chem. Lett. 2011, 2, 1189-1192.

(57) Tully, J. C. Molecular Dynamics With Electronic Transitions. J. Chem. Phys. 1990, 93, 1061-1071.

(58) Craig, C. F.; Duncan, W. R.; Prezhdo, O. V. Trajectory Surface Hopping in the Time-Dependent Kohn-Sham Approach for ElectronNuclear Dynamics. Phys. Rev. Lett. 2005, 95, 163001.

(59) Tully, J. C. Nonadiabatic Molecular Dynamics. Int. J. Quantum Chem. 1991, 40, 299-309.

(60) C. Tully, J. Mixed Quantum-Classical Dynamics. Faraday Discuss. 1998, 110, 407-419.

(61) Zhang, W.; Zhong, X.; Zhao, Y. Electron Mobilities of n-Type Organic Semiconductors from Time-Dependent Wavepacket Diffusion Method: Pentacenequinone Derivatives. J. Phys. Chem. A 2012, 116, 11075-11082.

(62) Kondov, I.; Cizek, M.; Benesch, C.; Wang, H.; Thoss, M. Quantum Dynamics of Photoinduced Electron-Transfer Reactions in Dye-semiconductor Systems: First-Principles Description and Application to Coumarin 343-TiO 2 . J. Phys. Chem. C 2007, 111, 11970-11981.

(63) Thoss, M.; Kondov, I.; Wang, H. Theoretical Study of Ultrafast Heterogeneous Electron Transfer Reactions at Dye-Semiconductor Interfaces. J. Chem. Phys. 2004, 304, 169-181.

(64) Kondov, I.; Thoss, M.; Wang, H. Theoretical Study of Ultrafast Heterogeneous Electron Transfer Reactions at Dye-semiconductor Interfaces:Coumarin 343 at Titanium Oxide? J. Phys. Chem. A 2005, 110, 1364-1374.

(65) Rego, L. G. C.; Batista, V. S. Quantum Dynamics Simulations of Interfacial Electron Transfer in Sensitized $\mathrm{TiO}_{2}$ Semiconductors. J. Am. Chem. Soc. 2003, 125, 7989-7997.

(66) Umari, P.; Giacomazzi, L.; De Angelis, F.; Pastore, M.; Baroni, S. Energy-Level Alignment in Organic Dye-Sensitized $\mathrm{TiO}_{2}$ from GW Calculations. J. Chem. Phys. 2013, 139, 014709.

(67) Ghosez, P.; Gonze, X.; Godby, R. W. Long-Wavelength Behavior of the Exchange-Correlation Kernel in the Kohn-Sham Theory of Periodic Systems. Phys. Rev. B 1997, 56, 12811-12817.

(68) Rubio, A.; Balbás, L. C.; Alonso, J. A. Influence of Nonlocal Exchange-Correlation Effects on the Response Properties of Simple Metal Clusters. Phys. Rev. B 1992, 46, 4891-4898.
(69) Marom, N.; Moussa, J. E.; Ren, X.; Tkatchenko, A.; Chelikowsky, J. R. Electronic Structure of Dye-Sensitized $\mathrm{TiO}_{2}$ Clusters from ManyBody Perturbation Theory. Phys. Rev. B 2011, 84, 245115.

(70) Faber, C.; Duchemin, I.; Deutsch, T.; Blase, X. Many-Body Green's Function Study of Coumarins for Dye-Sensitized Solar Cells. Phys. Rev. B 2012, 86, 155315.

(71) Patrick, C. E.; Giustino, F. Quantitative Analysis of Valence Photoemission Spectra and Quasiparticle Excitations at ChromophoreSemiconductor Interfaces. Phys. Rev. Lett. 2012, 109, 116801.

(72) Magyar, R. J.; Tretiak, S. Dependence of Spurious ChargeTransfer Excited States on Orbital Exchange in TDDFT: Large Molecules and Clusters. J. Chem. Theory Comput. 2007, 3, 976-987.

(73) Dreuw, A.; Head-Gordon, M. Single-Reference ab Initio Methods for the Calculation of Excited States of Large Molecules. Chem. Rev. 2005, 105, 4009-4037.

(74) Parac, M.; Grimme, S. A TDDFT Study of the Lowest Excitation Energies of Polycyclic Aromatic Hydrocarbons. Chem. Phys. 2003, 292, $11-21$.

(75) Grimme, S.; Parac, M. Substantial Errors from Time-Dependent Density Functional Theory for the Calculation of Excited States of Large $\pi$ Systems. ChemPhysChem 2003, 4, 292-295.

(76) Christiansen, O.; Koch, H.; Jørgensen, P. The Second-Order Approximate Coupled Cluster Singles and Doubles Model CC2. Chem. Phys. Lett. 1995, 243, 409-418.

(77) Taylor, D. J.; Paterson, M. J. Calculations of the Low-Lying Excited States of the $\mathrm{TiO}_{2}$ Molecule. J. Chem. Phys. 2010, 133, 204302.

(78) Grimme, S. Calculation of the Electronic Spectra of Large Molecules. Reviews in Computational Chemistry; John Wiley and Sons, Inc.: New York, 2004; pp 153-218.

(79) Parusel, A. B. J.; Grimme, S. A Theoretical Study of the Excited States of Chlorophyll a and Pheophytin a. J. Phys. Chem. B 2000, 104, 5395-5398.

(80) Berardo, E.; Hu, H.-S.; Kowalski, K.; Zwijnenburg, M. A. Coupled Cluster Calculations On $\mathrm{TiO}_{2}$ Nanoclusters. J. Chem. Phys. 2013, 139, 064313.

(81) Reining, L.; Olevano, V.; Rubio, A.; Onida, G. Excitonic Effects in Solids Described by Time-Dependent Density-Functional Theory. Phys. Rev. Lett. 2002, 88, 066404.

(82) Sottile, F.; Olevano, V.; Reining, L. Parameter-Free Calculation of Response Functions in Time-Dependent Density-Functional Theory. Phys. Rev. Lett. 2003, 91, 056402.

(83) Lee, C.; Yang, W.; Parr, R. G. Development of the Colle-Salvetti Correlation-Energy Formula into A Functional of the Electron Density. Phys. Rev. B 1988, 37, 785-789.

(84) Becke, A. D. Density Functional Thermochemistry. III. The Role of Exact Exchange. J. Chem. Phys. 1993, 98, 5648-5652.

(85) Becke, A. D. A New Mixing of Hartree-Fock and Local Density Functional Theories. J. Chem. Phys. 1993, 98, 1372-1377.

(86) Becke, A. D. Density-Functional Exchange-Energy Approximation with Correct Asymptotic Behavior. Phys. Rev. A 1988, 38, 30983100.

(87) Chai, J.-D.; Head-Gordon, M. Long-Range Corrected Hybrid Density Functionals with Damped Atom-Atom Dispersion Corrections. Phys. Chem. Chem. Phys. 2008, 10, 6615-6620.

(88) Dev, P.; Agrawal, S.; English, N. J. Functional Assessment for Predicting Charge-Transfer Excitations of Dyes in Complexed State: A Study of Triphenylamine-Donor Dyes on Titania for Dye-Sensitized Solar Cells. J. Phys. Chem. A 2012, 117, 2114-2124.

(89) Dev, P.; Agrawal, S.; English, N. J. Determining the Appropriate Exchange-Correlation Functional for Time-Dependent Density Functional Theory Studies of Charge-Transfer Excitations in Organic Dyes. J. Chem. Phys. 2012, 136, 224301.

(90) Lee, M.-J.; Balanay, M.; Kim, D. Molecular Design of Distorted Push-Pull Porphyrins for Dye-Sensitized Solar Cells. Theor. Chem. Acc. 2012, 131, 1269.

(91) Yanai, T.; Tew, D. P.; Handy, N. C. A New Hybrid ExchangeCorrelation Functional Using the Coulomb-Attenuating Method (CAM-B3LYP). Chem. Phys. Lett. 2004, 393, 51-57. 
(92) Vydrov, O. A.; Scuseria, G. E. Assessment of a Long-Range Corrected Hybrid Functional. J. Chem. Phys. 2006, 125, 234109.

(93) Vydrov, O. A.; Heyd, J.; Krukau, A. V.; Scuseria, G. E. Importance of Short-Range Versus Long-Range Hartree-Fock Exchange for the Performance Of Hybrid Density Functionals. J. Chem. Phys. 2006, 125, 074106.

(94) Vydrov, O. A.; Scuseria, G. E.; Perdew, J. P. Tests of Functionals for Systems with Fractional Electron Number. J. Chem. Phys. 2007, 126, 154109.

(95) Lynch, B. J.; Fast, P. L.; Harris, M.; Truhlar, D. G. Adiabatic Connection for Kinetics. J. Phys. Chem. A 2000, 104, 4811-4815.

(96) Zhao, Y.; Truhlar, D. G. The M06 Suite of Density Functionals for Main Group Thermochemistry, Thermochemical Kinetics, Noncovalent Interactions, Excited States, and Transition Elements: Two New Functionals and Systematic Testing of four M06-Class Functionals and 12 Other Functionals. Theor. Chem. Acc. 2008, 120, 215-241.

(97) Perdew, J. P.; Burke, K.; Ernzerhof, M. Generalized Gradient Approximation Made Simple. Phys. Rev. Lett. 1996, 77, 3865-3868.

(98) Kossmann, S.; Neese, F. Comparison of Two Efficient Approximate Hartee-Fock Approaches. Chem. Phys. Lett. 2009, 481, 240-243.

(99) Neese, F.; Wennmohs, F.; Hansen, A.; Becker, U. Efficient, Approximate and Parallel Hartree-Fock and Hybrid DFT Calculations. A "Chain-of-Spheres" Algorithm for the Hartree-Fock Exchange. Chem. Phys. 2009, 356, 98-109.

(100) Brooks, A.; Kaupp, T.; Makarenko, A.; Williams, S.; Orebäck, A. Orca: A Component Model and Repository. In Software Engineering for Experimental Robotics; Brugali, D., Ed.; Springer: Berlin; Heidelberg, 2007; pp 231-251.

(101) Neese, F. The ORCA Program System. Wiley Interdiscip. Rev.: Comput. Mol. Sci. 2012, 2, 73-78.

(102) Frisch, M. J.; Trucks, G. W.; Schlegel, H. B.; Scuseria, G. E.; Robb, M. A.; Cheeseman, J. R.; Scalmani, G.; Barone, V.; Mennucci, B.; Petersson, G. A.; et al. Gaussian 09, Revision B.01; Gaussian, Inc.: Wallingford, CT, 2009.

(103) Nosé, S. A Unified Formulation of the Constant Temperature Molecular Dynamics Methods. J. Chem. Phys. 1984, 81, 511-519.

(104) Marinado, T.; Nonomura, K.; Nissfolk, J.; Karlsson, M. K.; Hagberg, D. P.; Sun, L.; Mori, S.; Hagfeldt, A. How the Nature of Triphenylamine-Polyene Dyes in Dye-Sensitized Solar Cells Affects the Open-Circuit Voltage and Electron Lifetimes. Langmuir 2009, 26, 2592-2598.

(105) Preat, J.; Michaux, C.; Jacquemin, D.; Perpète, E. A. Enhanced Efficiency of Organic Dye-Sensitized Solar Cells: Triphenylamine Derivatives. J. Phys. Chem. C 2009, 113, 16821-16833.

(106) Mosconi, E.; Yum, J.-H.; Kessler, F.; Gómez García, C. J.; Zuccaccia, C.; Cinti, A.; Nazeeruddin, M. K.; Grätzel, M.; De Angelis, F. Cobalt Electrolyte/Dye Interactions in Dye-Sensitized Solar Cells: A Combined Computational and Experimental Study. J. Am. Chem. Soc. 2012, 134, 19438-19453.

(107) Fan, W.; Tan, D.; Deng, W. Theoretical Investigation of Triphenylamine Dye/Titanium Dioxide Interface for Dye-Sensitized Solar Cells. Phys. Chem. Chem. Phys. 2011, 13, 16159-16167.

(108) Xu, W.; Peng, B.; Chen, J.; Liang, M.; Cai, F. New Triphenylamine-Based Dyes for Dye-Sensitized Solar Cells. J. Phys. Chem. C 2008, 112, 874-880.

(109) Jiao, Y.; Ding, Z.; Meng, S. Atomistic Mechanism of Charge Separation Upon Photoexcitation at the Dye-Semiconductor Interface for Photovoltaic Applications. Phys. Chem. Chem. Phys. 2011, 13, 13196-13201.

(110) Pastore, M.; Fantacci, S.; De Angelis, F. Ab Initio Determination of Ground and Excited State Oxidation Potentials of Organic Chromophores for Dye-Sensitized Solar Cells. J. Phys. Chem. C 2010, 114, 22742-22750.

(111) Tian, H.; Yang, X.; Chen, R.; Zhang, R.; Hagfeldt, A.; Sun, L. Effect of Different Dye Baths and Dye-Structures on the Performance of Dye-Sensitized Solar Cells Based on Triphenylamine Dyes. J. Phys. Chem. C 2008, 112, 11023-11033.
(112) Persson, P.; Bergström, R.; Lunell, S. Quantum Chemical Study of Photoinjection Processes in Dye-Sensitized $\mathrm{TiO}_{2}$ Nanoparticles. J. Phys. Chem. B 2000, 104, 10348-10351.

(113) Marom, N.; Körzdörfer, T.; Ren, X.; Tkatchenko, A.; Chelikowsky, J. R. Size Effects in the Interface Level Alignment of Dye-Sensitized $\mathrm{TiO}_{2}$ Clusters. J. Phys. Chem. Lett. 2014, 5, 2395-2401.

(114) Amat, A.; De Angelis, F. Challenges in the Simulation of DyeSensitized ZnO Solar Cells: Quantum Confinement, Alignment of Energy Levels and Excited State Nature at the Dye/Semiconductor Interface. Phys. Chem. Chem. Phys. 2012, 14, 10662-10668.

(115) De Angelis, F.; Di Valentin, C.; Fantacci, S.; Vittadini, A.; Selloni, A. Theoretical Studies on Anatase and Less Common $\mathrm{TiO}_{2}$ Phases: Bulk, Surfaces, and Nanomaterials. Chem. Rev. 2014, 114, 9708-9753.

(116) Delley, B. An All-Electron Numerical Method for Solving the Local Density Functional for Polyatomic Molecules. J. Chem. Phys. 1990, 92, 508-517.

(117) Delley, B. From Molecules to Solids with the DMol3 Approach. J. Chem. Phys. 2000, 113, 7756-7764.

(118) Ahlrichs, R.; Bär, M.; Häser, M.; Horn, H.; Kölmel, C. Electronic Structure Calculations on Workstation Computers: The Program System Turbomole. Chem. Phys. Lett. 1989, 162, 165-169.

(119) Sierka, M.; Hogekamp, A.; Ahlrichs, R. Fast Evaluation of the Coulomb Potential for Electron Densities Using Multipole Accelerated Resolution of Identity Approximation. J. Chem. Phys. 2003, 118, 91369148.

(120) Persson, P.; Lundqvist, M. J.; Ernstorfer, R.; Goddard, W. A.; Willig, F. Quantum Chemical Calculations of the Influence of AnchorCum-Spacer Groups on Femtosecond Electron Transfer Times in DyeSensitized Semiconductor Nanocrystals. J. Chem. Theory Comput. 2006, 2, 441-451.

(121) Newns, D. M. Self-Consistent Model of Hydrogen Chemisorption. Phys. Rev. 1969, 178, 1123-1135.

(122) Kresse, G.; Hafner, J. Ab Initio Molecular Dynamics for Liquid Metals. Phys. Rev. B 1993, 47, 558-561.

(123) Kresse, G.; Joubert, D. From Ultrasoft Pseudopotentials to the Projector Augmented-Wave Method. Phys. Rev. B 1999, 59, 1758-1775.

(124) Blöchll, P. E. Projector Augmented-Wave Method. Phys. Rev. B 1994, 50, 17953-17979.

(125) Gouterman, M. Spectra of Porphyrins. J. Mol. Spectrosc. 1961, 6, $138-163$

(126) Chen, P.; Yum, J. H.; De Angelis, F.; Mosconi, E.; Fantacci, S.; Moon, S.-J.; Baker, R. H.; Ko, J.; Nazeeruddin, M. K.; Grätzel, M. High Open-Circuit Voltage Solid-State Dye-Sensitized Solar Cells with Organic Dye. Nano Lett. 2009, 9, 2487-2492.

(127) Pastore, M.; De Angelis, F. Computational Modeling of Stark Effects in Organic Dye-Sensitized $\mathrm{TiO}_{2}$ Heterointerfaces. J. Phys. Chem. Lett. 2011, 2, 1261-1267.

(128) Schiffmann, F.; VandeVondele, J.; Hutter, J.; Wirz, R.; Urakawa, A.; Baiker, A. Protonation-Dependent Binding of Ruthenium Bipyridyl Complexes to the Anatase(101) Surface. J. Phys. Chem. C 2010, 114, $8398-8404$.

(129) Rohrdanz, M. A.; Herbert, J. M. Simultaneous Benchmarking of Ground- and Excited-State Properties with Long-Range-Corrected Density Functional Theory. J. Chem. Phys. 2008, 129, 034107.

(130) Agrawal, S.; Dev, P.; English, N. J.; Thampi, K. R.; MacElroy, J. M. D. A TD-DFT Study of the Effects of Structural Variations on the Photochemistry of Polyene Dyes. Chem. Sci. 2012, 3, 416-424.

(131) Anselmi, C.; Mosconi, E.; Pastore, M.; Ronca, E.; De Angelis, F. Adsorption of Organic Dyes on $\mathrm{TiO}_{2}$ Surfaces in Dye-Sensitized Solar Cells: Interplay of Theory and Experiment. Phys. Chem. Chem. Phys. 2012, 14, 15963-15974.

(132) Cohen, A. J.; Mori-Sánchez, P.; Yang, W. Challenges for Density Functional Theory. Chem. Rev. 2011, 112, 289-320.

(133) Zhu, C.; Liang, J.; Cao, Z. Unique Metal Dicorrole Dyes with Excellent Photoelectronic Properties for Solar Cells: Insight from Density Functional Calculations. J. Phys. Chem. C 2013, 117, 1338813395.

(134) Lundqvist, M. J.; Nilsing, M.; Lunell, S.; Åkermark, B.; Persson, P. Spacer and Anchor Effects on the Electronic Coupling in Ruthenium- 
bis-Terpyridine Dye-Sensitized $\mathrm{TiO}_{2}$ Nanocrystals Studied by DFT. J. Phys. Chem. B 2006, 110, 20513-20525.

(135) Dreuw, A.; Weisman, J. L.; Head-Gordon, M. Long-Range Charge-Transfer Excited States in Time-Dependent Density Functional Theory Require Non-Local Exchange. J. Chem. Phys. 2003, 119, 29432946.

(136) Dreuw, A.; Head-Gordon, M. Failure of Time-Dependent Density Functional Theory for Long-Range Charge-Transfer Excited States: The Zincbacteriochlorin-Bacteriochlorin and Bacteriochlorophyll-Spheroidene Complexes. J. Am. Chem. Soc. 2004, 126, 40074016.

(137) Ronca, E.; Marotta, G.; Pastore, M.; De Angelis, F. Effect of Sensitizer Structure and $\mathrm{TiO}_{2}$ Protonation on Charge Generation in Dye-Sensitized Solar Cells. J. Phys. Chem. C 2014, 118, 16927-16940. 